\title{
3D Technology in Collaborative Heritage Preservation*
}

\author{
Medeia Csoba DeHass and Alexandra Taitt
}

\begin{abstract}
Digital repatriation is one aspect of heritage preservation work that has been increasingly gaining popularity due to its effectiveness in assisting Indigenous communities in connecting with museum collections located at various institutions around the world. It is not simply an alternative for physical repatriation; rather, the two can be used in conjunction, particularly with the incorporation of 3D technology. While digital repatriation can provide new opportunities, it is also a contested concept (Boast and Enote 2013) that is still in the process of shaping future collaborative practices while being shaped by ongoing projects and their outcomes. In this paper, we explore how this technology, structure from motion (SFM) 3D modeling and scanning, provides innovative methods that are especially well suited for successfully contributing to a wide array of heritage preservation objectives. Three-dimensional technology is effective in providing alternative ways to connect with collection pieces and providing origin communities access to museum collections. It can alleviate concerns of chemical exposure from contamination, concerns for the fragility of items, the expense of insurance and transportation, or the need to remove pieces from origin communities. As artifacts transform in the repatriation process by gaining new life and meaning when they enter the contemporary reality of the origin community, the use of 3D technology, as part of this collaboration, can assist Indigenous communities in fulfilling their own visions of heritage preservation.
\end{abstract}

[Keywords: digital repatriation; 3D technology; Indigenous peoples; Alaska Native; cultural heritage; historic preservation. Keywords in italics are derived from the American Folklore Society Ethnographic Thesaurus, a standard nomenclature for the ethnographic disciplines.]

\section{Introduction}

Museums are cultural spaces where items are hidden in plain sight. Collection pieces may spend decades lifelessly sitting on shelves, lurking in the shadows of renowned items, and waiting to meet a person who recognizes them for what they are: meaningful carriers of cultural knowledge. Of course, this might never happen. Whether due to outdated terminology, incorrect categorization, or inadequate information, most museums struggle to fully know their pieces and effectively share them with the public. Ethnographic museum collections are fundamentally stationary assets that cannot easily travel to origin communities or researchers due to their

\footnotetext{
This peer-reviewed contribution was accepted for publication in Museum Anthropology Review on July $17,2017$. The work is licensed under the Creative Commons Attribution 4.0 International License. To view a copy of this license, visit http://creativecommons.org/licenses/by/4.0/.
} 
immeasurable intrinsic, cultural, and artistic values. Moreover, issues with physical stability and fragility, potential chemical contamination due to prior preservation practices, and questions of cultural property rights also complicate such undertakings.

For these reasons, it is not surprising that most Indigenous communities have very little or no knowledge of the institutional locations of items that were created by their ancestors. Likewise, many scholarly specialists have a working knowledge of only the most explored collections, and often a handful of well-known pieces are continually reused as the best available examples of a certain type of artifact. Yet, there are many more presently unknown items sitting in museums waiting to be imbued with life through methods like digital repatriation to their origin communities and introduced to scholarly discourse to advance the current state of knowledge.

While digital repatriation - here understood as the practice of taking some digital form of an item housed in a memory institution and sharing it with the origin community via a virtual platformcan provide new opportunities, it is also a contested concept that is still in the process of shaping future collaborative practices while being shaped by ongoing projects and their outcomes. It neither assumes nor denies the possibility of physical repatriation; rather, it focuses on sharing information with origin and descendant communities by creating a knowledge-sharing network. While items are currently residing residing away from their origin communities at memory institutions such as museums, the intangible aspects of local heritage that were created in the origin communities were removed with the item. Yet, this intangible cultural heritage can be returned to origin and descendant communities via digital repatriation to become an active part of the contemporary living culture (Gill 2001,2).

According to Cory Willmott and her colleagues $(2016,92)$, digital repatriation has been gaining popularity in usage as it focuses on the "return of digital reproductions of heritage items," while "virtual repatriation" is falling out of use because it "seems to misleadingly suggest a fake kind of actual return" and "members of source communities" prefer the former to the latter. Joshua Bell, Kim Christen, and Mark Turin $(2013,5)$ summarize the emergence of digital repatriation as a response to the lack of proper facilities and social-political support that are needed for a successful physical repatriation. As such, digital repatriation can provide an alternative avenue for sharing information about the original items. It is also a "distinct practice in its own right" (Bell, Christen, and Turin. 2013, 5) that, like technological innovation, continually evolves based on lessons learned from each project using this approach.

In 2009, Kate Hennessy $(2009$, 6) defined virtual repatriation as "visual access by [origin] communities to their cultural heritage in online museum and ethnographic collections." At the time, virtual repatriation, describing the use of new technologies for connecting institutional collections with their descendant and origin communities in cyberspace, was a prevalent and accepted term. In 2013, Boast and Enote questioned whether virtual repatriation is repatriation at all and concluded that while the work of reconnecting origin communities with their material culture is important, the term virtual repatriation is counterproductive to empowering origin communities. As a result, and based on the Zuni interpretation of repatriation, virtual repatriation has gained a negative connotation with the aforementioned assumption that it offers fake repatriation. 
Alternatively, Aaron Glass (2015) believes there is merit to the process, but it should be made clear what virtual repatriation can and cannot achieve. Glass makes a major distinction between physical objects and their digital renderings, which also include associated cultural knowledge expressed in a digital format, as he argues that repatriation should only be used for the return of physical artifacts. He proceeds to coin the term e-patriation, which he defines as "the transfer of tangible or intangible cultural patrimony (or heritage material) to its source community in the form of electronic or digital media" (Glass 2015, 23) that also includes the return of digital objects. While this approach sheds light on the difference between the physical object and its digital rendering as potentially two different, albeit related, articulations of a cultural-specific item, $e$ patriation does not convey a crucial part of the process-namely, the process of returning something culturally meaningful to origin communities. Others are particularly in favor of the potential digital networks hold for meaningfully connecting collection pieces with local knowledge and members of origin communities (Basu 2013; Bell et al. 2013; Bohaker, Corbiere, and Phillips 2015; Hennessy 2009; Hennessy et al. 2013; Morphy 2015; Resta et al. 2002; Rowley et al. 2010; Shannon 2015).

For these reasons, the term digital repatriation is resurfacing in the discourse on digital representation of Indigenous peoples, decolonizing heritage institution collections, and indigenizing the collection process. It would be incorrect to assume that all Indigenous people wish to get the original physical item back just because some origin and descendant communities do. As we discuss later, access - meaning continuous and reliable access - to Indigenous collections is just as significant as physical repatriation, particularly in cases when the latter is difficult to attain due to the lack of legally binding regulations. This is often the situation with Arctic and Subarctic collections.

As Timothy Powell (2016) recently reflected regarding his experiences at the Center for Native American and Indigenous Research at the American Philosophical Society, some communities do not wish to have original documents back. As the center's Kwakwaka'wakw partner explained, the origin community is more interested in having access to the materials so that they can interpret them from their own culturally specific point of view (Powell 2016, 67).

Using the exact same words as the center's Kwakwaka'wakw partner, "we've been studied to death," Eva Malvich (2016), the curator and director of the Yupiit Piciryarait Museum http://www.avcp.org/services/yupiit-piciryarait-museum/ of Bethel, explains her opinion on being thankful for those who have recorded Yup'ik history and traditions in the past so that it can be read and interpreted by Yup'ik people today. She also expresses the importance of learning about a collection piece even if it is located in a museum. Through the knowledge that is shared with her as an origin community member, she takes pride in a piece that came from her hometown and is now being studied at various institutions around the world. Malvich also believes that expecting the return of all pieces that have ever been taken from origin communities can be naive, because taking back collections (in her example, a mask) means taking on a lot of responsibility in providing suitable facilities and care. In this sense, knowing about the existence of the collection and being provided with the possibility of learning from the collection - in other words, having access to it-are more important than physically owning the pieces. From Malvich's perspective, she is still meaningfully connected to the pieces in museum collections and they are part of the cultural and intellectual heritage of her community. 
Increasing access in general, is one of the major hallmarks of the digital repatriation framework (Silverman 2015, 6). In a recent talk, Alutiiq carver Perry Eaton (2016) discussed his experiences of working with the Alphonse Pinart Alutiiq mask collection of the French museum of Boulognesur-Mer. He specifically highlighted the significance of access to the masks and the knowledge they hold over the importance of physical repatriation. As an Alutiiq carver, his focus was on learning about the masks, such as the carving techniques used in making them, and the information that can be gleaned from the masks about Alutiiq ancestors.' Whether the masks were located in France, Washington, DC, or Anchorage, Alaska, had little significance for Eaton as he considers these masks to belong to him and all Alutiiq people as long as the origin communities have continual and consistent access to them. As part of this access, Eaton and other project participants put together several publications that showed multi-angle images of the masks. These publications were distributed to shareholders and widely circulated in the Alutiiq region.

Sven Haakanson (2015; in Rostkowski 2012, 33-34) expresses similar sentiments when describing his work with Alutiiq artifacts held at various institutions around the world. Haakanson emphasizes the importance of building relationships with museums and institutions and acknowledges the care museums have been providing to preserve these artifacts. As he explains, through these reciprocal long-term relationships, he hopes to "keep doors open" should an international version of the Native American Graves Protection and Repatriation Act (NAGPRA) https://www.nps.gov/nagpra/ come into existence in the future and make physical repatriation across national boundaries possible (Haakanson 2015).

Similar to some Alutiiq people (Ginsburg 2008, 90; Haakanson in Rostkowski 2012, 33; Haakanson and Steffian 2009, 15), the Yup'ik elders who visited the Johan Adrian Jacobsen Collection at the Ethnologisches Museum in Berlin also expressed gratitude to the institution for caring and preserving their ancestors' heritage (Fienup Riordan 2005, 285). In particular, they were pleased to find many pieces, such as masks, at the museum that no longer exist in the communities today. ${ }^{4}$ The elders brought back many photos of these artifacts to show their communities, which Ann Fienup Riordan referred to as "visual repatriation." Since then, "turning fieldwork on its head" (Fienup Riordan 2005) by bringing elders to museums in order to work with the collection pieces and share information about them has become an effective and widespread practice for incorporating traditional knowledge into collaborative collections management (e.g., Alaska Native Collections Sharing Knowledge https://alaska.si.edu/; Dawson, Levy, and Lyons 2011; Inuvialuit Living History http://www.inuvialuitlivinghistory.ca/; Looking Both Ways; Yuungnaqpiallerput-The Way We Genuinely Live_https://naturalhistory.si.edu/lookingbothways/).

These collaborations, in turn, shape the larger conversation developing around the idea of digital repatriation. The phenomenon known as "knowledge repatriation" (Dawson et al. 2011) grew out of this larger discourse focusing on the process of incorporating digital technologies to preserve traditional and elder knowledge and to engage younger generations with information they may not be interested in otherwise. With sharing and virtually representing Indigenous and elder knowledge, a new variation of an old concern regarding protecting Indigenous intellectual property 
and heritage surfaced. As origin communities became aware of the challenges that came with the easy digital dissemination of their traditional knowledge to the entire world with a click of a button, they realized the need for a variety of controls that would help them mindfully share what they thought was appropriate for the internet (Bohaker et al. 2015; Brown and Nicholas 2012; Christen 2009; Hennessy 2009; IPinCH, https://www.sfu.ca/ipinch/; Local Contexts, http://localcontexts.org/; Morphy 2015; Mukurtu, http://mukurtu.org/).

Regardless of opinions on the effectiveness of digital repatriation, there are considerations that must be accounted for with this relatively young collaborative process. Museums and heritage institutions have a long history of collaborating with "individuals . . . as representatives of their cultural communities" (Black 2013, 787), and museums also relied on paper catalogs to share information about their collections with the public, including origin communities. Yet digital repatriation has opened new avenues for collaboration, sharing information, and working with origin and descendant communities.

Often, paper catalogs were distributed to known origin communities and placed in the reference sections of archives and libraries. As such, they did reach some segments of origin and descendant communities. Despite the best efforts of curators and collection managers, paper catalogs were limited in their success for several reasons. Due to printing and distribution costs, only a limited number of pieces could be featured. Catalogs themselves were often costly, partially also due to the cost associated with producing a high-quality catalog, which limited access to those able to purchase the catalogs or have access via libraries and other heritage institutions. Therefore, many Indigenous communities had no access to the catalogs featuring their heritage.

When compared with paper catalogs, digital repatriation platforms provide equal access to a larger number of users such as known and potentially unknown origin and descendant communities, opportunities for collaboration with origin communities in the ongoing curation of the material on the digital platform, flexibility in curation as the information is not circulated in print form, integrated access to multimedia information, and an opportunity to redefine power relations embedded in representations of Indigenous peoples through their material heritage.

As anthropologists turn to digital methods for making museum and archival collections more available (Salmond 2012) and employ new technologies to contextualize and disseminate ethnographic material, it is important to consider the ethical implications of the "digitization and circulation of cultural heritage" (Hennessy 2009, 5). These new forms of media have the potential to strengthen bonds between researchers and origin communities, but if not used with continual community input and built to reflect local ontologies, they may also have the "potential to disrupt the sense of trust and collaboration" (Hennessy 2009,6). When digital ethnographic websites are built collaboratively with origin community members, the need to protect some aspects of local heritage can result in limited access and stricter protocols. Even though this may initially frustrate users outside the target community, culture-specific contextualization of these limitations can help us move toward responsible ethical practices in digitally sharing Indigenous cultural heritage (Christen 2009).

A decade and a half ago, Tony Gill $(2001,2)$ discussed the potential benefits 3D technology can offer for "memory institutions" such as museums and repositories. Chief among these was the 
ability to offer a cost-effective solution for balancing the two main mission goals of museums: preserving collections and providing access. Gill also briefly discussed the advantage of using 3D technology in digital repatriation, but his main focus was on reviewing and evaluating digitization technologies that could provide some form of $3 \mathrm{D}$ visualization. At the time, this was a muchneeded discussion, as most 3D applications originated outside of the cultural heritage management field. Since then, technologies for creating digital models has shifted from primarily industrial and software applications to extensive use in the field of cultural heritage preservation (Scopigno et al. 2011).

Traditionally, cultural heritage has been documented by drawings and photographs, which can be time consuming and limiting when it comes to capturing the entire essence of the item. Massimiliano Pieraccini, Gabriele Guidi, and Carlo Atzeni (2001) highlight some of the benefits of 3D digital imaging in cultural heritage as conservation, study, and restoration of works. Creating 3D models also allows more in-depth study of artwork and helps overcome obstacles such as geographical distance, operating hours, or limitations due to concerns over accessing the physical items. In archaeological contexts, 3D models simultaneously provide visual, spatial, and timespecific information (Scopigno et al. 2011). In fact, 3D technologies, especially scanning (PatayHorváth 2014; Tal 2014, 50), have been quickly adopted by archaeologists as an efficient and costeffective fieldwork method (Bruno et al. 2010; Corns et al. 2015; Gill 2001; Tal 2014, 52; Weber 2013), when compared with drawing by hand. While 3D technologies have also been used to document excavation sites (Gill 2001; Younan and Treadaway 2015), restore fragmented artwork, and correct accurate paint colors by piecing together parts of an item and stitching them into a whole model (Scopigno et al. 2011), museums, and especially ethnographic collections, have been much slower to adopt 3D technologies. This is not particularly surprising given the difficulties with capturing and modeling soft, shiny, or composite materials, a topic we will later discuss in detail.

The truth is, it takes time to create a good 3D model whether scanners or structure from motion (SFM) photogrammetry is used. Both methods require hours of cleanup and preparation as well as training on the proper use of the equipment. For these reasons, even today, most projects target specific items and handpick objects from collections for 3D digitization. Yet the items being picked are highly dependent on the curatorial rationale and the project's goals. For instance, relevant literature, third-party 3D content management sites, and prolificacy of SFM photogrammetry program development suggest that 3D modeling for heritage preservation is less prevalent in the United States than in the rest of the world.

The Zamani Project (http://www .zamaniproject.org/) creates 3D models of heritage sites in Africa specifically to digitally document endangered heritage landmarks and buildings. One of the goals of the Pure Land: Inside the Mogao Grottoes at Dunhuang Project (http://www.acim.cityu.edu.hk/projects/pure-land-ii-2012/) is also heritage preservation, but the collaborators included a robust cultural heritage interpretation segment that allows for a traveling exhibit using augmented reality. Many European projects appear to be focusing on famous landmarks and heritage objects as their first 3D models, those they can expect their viewers to be familiar with. These projects are digitizing and displaying their own national heritage, creating digital representations of national icons that are symbols of patriotism and are instantly recognizable both within and outside the culture, as for example the Michelangelo Project, which 
3D-modeled segments of the Porta del Paradiso in Florence (Pieraccini et al. 2001, 63). Recently, projects have been increasingly moving toward digitizing all collections and making them available to the larger public in formats that crosscut national boundaries and, at the same time, emphasize a shared European heritage. For instance, the Europeana Collections website (https://www.europeana.eu/portal/en/about.html), partially sponsored by the European Union, is an interactive platform serving up 3D models, digitized audio and video files, photographs, and archival documents. Its mission is to share information about European heritage with the greater public as well as to help people "discover a treasure of [their] own," browsing the over fifty million digital artifacts.

The Heritage Together project (Raimund et al. 2014) takes a crowdsourcing approach to preserving the Welsh heritage of the Gwynedd area. As they turn to locals with their request to share personal photos of monuments, places, and cultural heritage with the team of archaeologists and computer scientists from three different institutions, they draw on the opportunity to co-create heritage with the local community. Furthermore, by tapping into a collection of privately owned photographs, the project can create alternative views of local heritage that documents change over time. Likewise, the National Technical University of Athens used crowdsourcing to create a 3D model of the Plaka bridge, which was destroyed in 2015 due to extreme weather (Stathopoulou et al. 2015).

In contrast to the previous projects, the Danish National Museum's Skin Clothing Online digital collection (http://skinddragter.natmus.dk/) diverges from the trend focusing on visualizing national heritage as it displays high-quality 360 degree models of Indigenous gut, fur, and skin parkas from around the Circumpolar North. Similar to many projects working with Indigenous communities, it is digitizing somebody else's heritage as it concentrates on making things available that are little known except in oral history. It is not uncommon for origin community members to have heard about a specific item in a story or by elders yet never have seen one because their ancestors ceased making them and all the previous examples have been destroyed or removeduntil, of course, one such item is found on a shelf of a museum potentially thousands of miles away from the origin community, which is a common occurrence for many Alaska Native belongings (Fienup Riordan 2005; Haakanson 2012, 2014; Lepola 2013).

\section{What Is Digital Repatriation?}

As we previously outlined, digital repatriation, on a very basic level, is the practice of taking some digital form of an item housed in a memory institution and sharing it with the origin community via a virtual platform. The process can be based on the premise that "rather than being viewed as autonomous or self-evident, artifacts can be seen being shaped by and shaping complex networks of influence" (Burdick et al. 2012, 18). In this sense, museum collections and individual artifacts can transform during the digital repatriation process, take on cultural significance, become locally meaningful symbols, or gain new life and meaning by entering the contemporary reality of the origin community. The culturally specific interpretation of collection pieces is also influenced by opinions, reflections, attributions, discussions, and reinterpretations. These interactions, which Raymond A. Silverman $(2015,5)$ refers to as "a catalyst for translational engagements," all contribute to a knowledge base built on Indigenous epistemologies (e.g., Csoba DeHass and 
Bradley 2014; Inuvialuit Pitqusiit Inuuniarutait: Inuvialuit Living History, http://www.inuvialuitlivinghistory.ca; Muntean et al. 2015; Solomon and Thorpe 2012; Yuungnaqpiallerput - The Way We Genuinely Live, http://www.yupikscience.org; Yuuyaramek Elitnaurutkat, https://lksd.mukurtu.net/).

In its most elementary form, digital repatriation neither negates the possibility of nor promises to achieve the physical repatriation of collection pieces to origin communities. Its central tenet is to provide a connection between institutional collections and origin communities in a digital space by sharing information, facilitating discussion, and returning some form of cultural knowledge. For the digital repatriation to occur, there must be an active interaction between the digital material and origin community members, not simply the displaying of digital images on the internet as, for instance, in an online museum catalog. As the previously quoted Perry Eaton highlights the significance of access to collections and the knowledge that can be gained from them, what is being repatriated is not the physical object but the knowledge, information, and perhaps preserved cultural context. If we do not look at the item in itself as the only thing that can be repatriated, but we also consider the knowledge about, and embedded in, the item as cultural heritage that can be returned, it is clear that digital repatriation using 3D technology can play a crucial role in collaborative heritage preservation. Three-dimensional models can help people "[take] ownership of [their] cultural heritage" (Younan and Treadaway 2015,246) as they can engage with the pieces on their own terms. Three-dimensional rendering of physical items can provide information that is difficult to perceive in real life, such as enlarged details and accurate measurements. It also allows for each origin community member to personally engage with the piece, manipulate it in digital space, observe it, and connect it with different areas of his or her own cultural understanding. Moreover, 3D supports the decolonization of preservation and documentation practices, as 3D models and point clouds can remain with the institution, with permission from the origin community, while the original physical piece can be repatriated (Hollinger et al. 2013).

If we step away from the digital-physical repatriation dichotomy and look at digital repatriation as one element of the repatriation process that can be complementary to physical repatriation, it becomes possible to view it as a powerful tool Indigenous communities can use to work toward reconnecting with and reclaiming their cultural heritage. In general, digital repatriation projects can engender museum exchange and temporary visits of pieces to origin communities that will make these pieces more available to origin community members and their descendants. This is particularly important in the case of items that are owned by institutions in countries where physical repatriation is not required by law. The previously discussed cases of the Yup'ik pieces of the Jacobsen collection in Berlin and the Alutiiq masks in France, as well as Sven Haakanson's (2015) reflection on the significance of the latter project as creating a relationship with those who owned the items, highlight the advantages of viewing repatriation as a process. While it may not be possible to physically repatriate items in the present, if it becomes possible at a later date, the connection that already exists will greatly help and, in a way, continue the process. Moreover, it can also extend the connection, both in space and time, that origin community members create with these pieces during temporary visiting exhibitions (Sharing Knowledge Website, https://alaska.si.edu/; Yuungnaqpiallerput-The Way We Genuinely Live, http://www.yupikscience.org). While physical repatriation is the ultimate goal of many Indigenous communities, it is presently not always an attainable goal, particularly in the instance of collections residing outside the United States or items that do not fall under NAGPRA. In these cases, digital 
repatriation can serve as an avenue for sharing information about pieces that are currently not possible to physically repatriate but might, at some point in the future, be discussed in some form of physical repatriation. Whether theorizing about possible international agreements that may eventually regulate the physical return of collection pieces across international boundaries or considering the physical return of pieces under NAGPRA, digital repatriation projects can lead directly to physical repatriation by creating avenues for sharing knowledge about collections and thereby providing the initial step: access.

Finally, physical repatriation does not equal legal repatriation. Satisfying the legal requirements of NAGPRA does not automatically mean that the repatriated item will be returned to the origin or descendant community it came from. In these cases, Indigenous communities can use digital repatriation as a bridge between origin community members and their items, even after the legal process of repatriation has already taken place and the objects are physically in the possession of the legal representatives of the origin community.

Arctic and Subarctic collections are a good example of the interstice between legal and physical repatriation. In Alaska, unlike in the Lower 48, there are very few tribal museums, and those that do exist are located in regional hubs. Returned collection pieces are often stored in federal repositories in Anchorage or at one of the regional hubs. Even if an item is returned to a tribal museum, it may still be removed from its origin community by as far as several hundred miles. Taking the logistical challenges and great expense of Arctic travel into consideration, these distances can be prohibitive and actively prevent many origin community members from ever visiting or engaging with these legally repatriated items in real life. From their point of view, items could be in Anchorage or halfway around the world, yet the result will be exactly the same: complete lack of engagement with origin community members.

Reasons for not returning such items to their origin or descendant communities can be manifold. Regional politics can prevent the physical return of items, as they involve power struggles among village councils, village ANCSA (Alaska Native Claims Settlement Act) corporations, and regional ANCSA corporations. Regional corporations frequently, but not always, represent rural villages within their own region in NAGPRA matters. Sometimes two villages are only a few miles apart and share family ties, local histories, and close cultural connections, but one of them designated the regional corporation to represent them in NAGPRA cases, while the other did not. Often, items cannot be returned to their communities because the place where the items came from is currently uninhabited, the descendants having moved to different villages across the region. In this case, the decision needs to be made by the organization that officially represents the origin community in NAGPRA matters, and it generally finds a repository at regional facilities. Another common reason for keeping items in Anchorage and in regional hubs is the lack of infrastructure, trained personnel, and financial base needed for maintaining a local cultural repository in the origin community. As a result, it is not uncommon for most members of a community to have no knowledge of collection pieces that have been legally repatriated to them under NAGPRA, yet they continue to exist outside the community's everyday reality. If communities do know about the pieces, they often wish to bring them home, but they want to do it the right way, according to their own cultural understanding. 
In these cases, digital repatriation, especially when coupled with $3 \mathrm{D}$ technology, can provide a temporary alternative to communities that currently have no appropriate facilities to house already repatriated items. For example, I (Csoba DeHass) recently discussed the possibility of creating a digital repatriation website for an archaeological collection owned by an Alaska Native ANCSA village corporation that is the legal representative of its Alaska Native village in NAGPRA claims. The collection in question is currently housed at a federal institution because the museum facility in the origin community cannot provide appropriate storage and dedicated personnel for the pieces at this time and there is no tribal museum for this particular Alaska Native region. As an alternative, the corporation was considering a project during which the pieces were to be $3 \mathrm{D}$ modeled for community use and digitally repatriated through an interactive platform, while the collection itself was kept in a climate-controlled, curated facility until a later date. Digital repatriation as a way to return knowledge that was once removed from the community when the culturally significant items this knowledge was embedded in were removed complements the physical return of these items. Moreover, it enhances the repatriation process in a way that was not possible by the simple physical repatriation that satisfied the legal requirements set by NAGPRA. Digital repatriation would, therefore, allow origin community members to effectively, meaningfully, and collectively engage with these pieces by sharing knowledge about them on their own terms. Using digital repatriation after the legally required physical repatriation has taken place to return knowledge by providing access to the collection, Indigenous communities can make decisions about the kind of repatriation that fits their needs, individual circumstances, and heritage preservation goals. In this sense, digital repatriation is not viewed by all Indigenous communities as a hindrance that prevents them from being reunited with their heritage; rather, some communities view it as a valuable asset that can be used according to their local context and ontology to bring about a solution that works from their perspective.

\section{D Technology in Digital Repatriation}

The first notion 3D technology often brings to mind for both researchers and the greater public is 3D printing. Three-dimensional printing, the most tangible form of using 3D technology and producing 3D artifacts (Younan and Treadaway 2015,243), has been in the forefront of publicizing $3 \mathrm{D}$, circulating information about the use and benefits of this technology, and making it accessible and appealing to a large segment of society from medical applications through prototyping to $\mathrm{K}-$ 12 education. For these reasons, it is important to acknowledge that in this paper we are not discussing 3D printing; rather, our focus shall be on creating digital 3D models and examining their life, impact, and consequences in this digital space.

Three-dimensional printing is an exciting prospect that is also fraught with its own problems, some of which are discussed by Hollinger et al. (2013) and Turner (2015). This project made it clear that their work - namely, rendering a 3D replica of a Tlingit Killer Whale clan hat and a Tlingit rattle from the Alaska Native village of Hoonah with the purpose of repatriating the original artifacts and keeping the replicas at the Smithsonian Institution - was, in fact, not virtual repatriation. The items in question were physically repatriated to the origin communities, and in the repatriation process, the Smithsonian received permission from the clan and tribal leadership to create replicas. Through this project, Hollinger et al. were able to explore questions of collaboratively producing replicas, the relationship between the original item and its 3D replica from the perspective of 
Tlingit ontology, and expanding the use of 3D technology in a community setting beyond 3D printing by using 3D scanning and SFM.

As previously outlined, 3D modeling, in conjunction with an interactive digital platform, can achieve a variety of goals and agendas. Of these, the ability to reunite Indigenous communities with some aspect of their material cultural heritage through outreach and information-sharing activities is the most fundamental. In this process, researchers, institutional collection staff, and local stakeholders converge and jointly create a digital space that connects museums and origin communities through collaborative curation and continuous data sharing. According to Ivan Boserup (2005, 173), "in many cases links between such portals, or cross-national projects encompassing groups of documents or artefacts, will recreate and display the multiple interconnections and historical contexts of particularly remarkable cultural heritage materials that have been fragmented and dispersed during the course of history." In this sense, through digital repatriation, many Indigenous communities can learn about collection pieces that were once removed from their regions.

Of course, not all 3D technology or even collection digitization activities would fall under digital repatriation. Many large museums and archives struggle with the same concept: balancing their capacity to provide online access to their materials with the meaningful curation of digital information and artifacts (Leopold 2013, 87-88). While there are excellent digital collection management platforms and systems, such as Mukurtu (http://mukurtu.org/) and the Reciprocal Research Network (https://www.rrncommunity.org/), that specifically target the active curation of digital content, most museums do not have the ability or the resources to make all their pieces and collections available in this format. For these reasons, their focus is on digitizing records, providing high-resolution digital photos, and offering a venue to accept feedback from potential users. Because there is no active curation taking place, it is up to researchers and origin community members to find the information, although some umbrella sites, such as OpenGLAM_ (https://openglam.org/) and Digital Return (http://sustainableheritagenetwork.org/community/digital-return), do exist.

Many large museums - and in this particular case, we are focusing on those that have sizable Arctic collections, such as the Ethnologisches Museum in Berlin, the Burke Museum, the British Museum, the Scott Polar Research Institute's Museum, and the Smithsonian Institution's National Museum of Natural History - and even some of the smaller regional museums maintain online catalogs that are searchable and provide some information to the public on their substantial ethnographic collections. Admittedly, it is tremendously useful to have $24 / 7$ web access to these pieces, but none of these websites provide opportunities for lasting and meaningful interactions that can be had on a regular basis by the greater public. Additionally, it is often difficult to successfully locate collections and items that are relevant to the searcher's query, and it is even more challenging to produce results that are consistently replicable. Antiquated terminology and mislabeling are everyday realities of all museums as institutions often cannot afford to have experts on their staff for each of their collections. For these reasons, online catalogs still remain impenetrable to most users, and their contents largely exist outside shared knowledge. 
In comparison, when 3D modeling is used as part of a collaborative, curated digital platform, projects can convey information that reflects viewpoints other than that of a researcher, a curator, a collection manager, or a conservator. In this interactive digital environment, pieces are no longer disassociated objects on a shelf that need to be closed off from use. Rather, they are somebody's heritage that needs to be protected by sharing information about them in a culturally appropriate manner.

Three-dimensional models have the capability to show dimension, scale, close-up detail, and all sides of a piece in a way that surpasses multiple $2 \mathrm{D}$ shots of an item. They can also be used for precise measurements and run through computer programs and databases to be compared against existing typology (Gienko and Terry 2014). From the origin community members' perspective, photos or models that allow the examination of the techniques, materials, and preparation employed to make an item are far more important than the traditional cataloging photo that is shot from one angle with a scale in the corner of the frame (Csoba DeHass 2014; Eaton 2016). Origin community members wish to see the inside of baskets and the backs of masks, which can shed light on how a piece was made and used. They also want to see zoomed-in views of stitching on the sleeve of a parka and the beads on a headdress. These details can help ascertain ownership, convey information about the artists and makers of the items, and carry information about techniques and technology that may have been lost over time. A weaver can study a stitch in detail, understand and interpret the technique, use it to create contemporary pieces, and pass down the information as part of that particular Indigenous group's identity (Frontier Scientists 2016). Similarly, a carver can identify species of wood that were used in the past for mask making or producing household items but perhaps are no longer considered proper mediums due to the loss of information during the colonial past. As a result, the information about these pieces and some aspect of the items themselves will reenter the origin community's cultural landscape as they acquire new meanings and lives through the connections Indigenous peoples create with them based on their culturally specific interpretations.

Eaton $(2009,172)$ remarks about the Pinart Collection, "No single body of collected material has impacted the Sugpiaq Native arts community more significantly . . . [and] it has proven to be a fountain of inspiration and pride to people of the island." In turn, the information shared through this process can return to the institution holding the collection and can be used in future collection care, teaching materials, interpretive content, and exhibition texts. If the community decides to share these 3D models and their culturally specific interpretations, the information can also feed back into scholarly discourse. The process provides an avenue for origin community members to both directly and indirectly participate in forming the way they are represented to the greater public. Moreover, it also deconstructs lingering colonial legacies of the collection and heritage preservation process, promotes the recognition of Indigenous and local knowledge as equal to scholarly knowledge, and shifts existing power hierarchies to privilege local perspectives in representing local knowledge.

In addition to injecting new cultural knowledge into scholarly discussions about previously unknown items through the process of digital repatriation, 3D models can also assist origin communities in using their own Indigenous epistemological understandings to create a conceptual identity for these newly introduced pieces. As mentioned previously, the first projects using 3D technology had a tendency to focus on well-known masterpieces, and their area of concentration 
was often European antiquities as research teams created 3D digital models of their own nations' cultural heritage (e.g., Europeana Collection), and for these reasons, the issue concerning the digital representation of the cultural "Other" never really surfaced as part of the interpretation process. The situation is very different in the case of Indigenous collections. Many Indigenous collections are held as national possessions of foreign nations, with a long colonial history attached. Until the past fifteen years or so, Indigenous communities had no or very little say in how these items were handled, exhibited, interpreted, and used in creating an image about the culture and the descendants of the original owners (Brown and Peers 2003, 1). Three-dimensional technologies can provide opportunities to incorporate Indigenous epistemologies in contextualizing and presenting collection pieces on the internet in a manner that furthers specific goals and agendas of the origin community (Glenbow Museum 2008).

Due to 3D technology's capability to render detailed models, it is possible to highlight groups of items, perhaps scattered around the world in real life, as an intellectual unit not only as masterpieces in their own rights but also as powerful and articulate representations of their origin communities and cultures. What needs to be highlighted and contextualized can be different in the origin community's perspective than the museum professional's. In this sense, 3D technologies used as part of digital repatriation projects can create an ongoing discourse on a local-global continuum that requires the negotiation of meanings and representation in the collaborative curation of museum collections.

\section{SFM 3D Models in Heritage Preservation}

There are some general practical issues that make 3D technology, and in particular SFM 3D modeling, a well-suited method of heritage preservation. Due to the nature of prevalent preservation procedures used in the past 150 years, many ethnographic pieces in collections all around the world are contaminated with dangerous chemicals (Odegaard 2004, 75). During a visit to the Ethnologisches Museum in Berlin to work with the previously unknown portion of the Johan Adrian Jacobsen collection, a waiver had to be signed due to exposure to excessive DEET, mercury, and arsenic, despite complying with the compulsory requirement of wearing full-body suits, gloves, and respiratory masks. These circumstances are not unique to this particular museum (Odegaard and Sadongei 2005), but they can considerably limit the kind of access certain groups of people, such as elders, children, pregnant and nursing mothers, or people with weakened immune systems, can have to these collections. Moreover, it is often not possible to clean these items as high-power vacuuming or cleaning procedures would destroy the artifacts. An additional consideration is a concern regarding exhibition and transport, as all such items must travel and stay in self-contained, airtight containers and display cases in order to prevent the spread of toxicity. For these reasons, the best option for studying these collections may be a 3D approach with a collaborative platform, which also allows for digital repatriation and a connection with origin communities.

The second issue is the question of portability of technology across international borders. Based on regulations and logistics, the use of 3D scanners at international collections may be limited or impractical due to export control regulations and other concerns. Even mobile units can be difficult to transport and calibrate at new locations. Even if the use of 3D scanners were permitted at every 
museum collection, there are still further concerns about quality and the currently unforeseeable damage that may surface at a later date as a result of exposure to laser scanning (Callet 2014, 136). Furthermore, the quality of the scans relates directly to the cost of the scanner, requiring extremely expensive equipment to produce the very best 3D images. While the less-expensive models do have the capability to create acceptable scans, there are limitations to modeling certain materials. Typically, hard materials such as bone, stone, wood, and items with well-defined angles model fairly well, but other textures commonly found in museum collections are not produced as successfully. These materials include shiny surfaces such as glazes, varnishes, and enamels (Callet 2014, 137) and soft textures such as fur, gut, skin, cloth, and feathers. Although more expensive 3D scanners may produce higher-quality scans of both types of materials, the cost may outweigh the benefits.

The following three images depict the same checkbook cover made by Sugpiaq artist Nina Kvasnikoff. The checkbook cover's body is leather with glass and plastic beads decorating the front and the sides. The first image (figure 1) is a 2D photograph and the second image (figure 2) is of a 3D model that was laser-scanned. The third image (figure 3) is of a 3D model that was created using SFM photogrammetry by the Agisoft PhotoScan program.

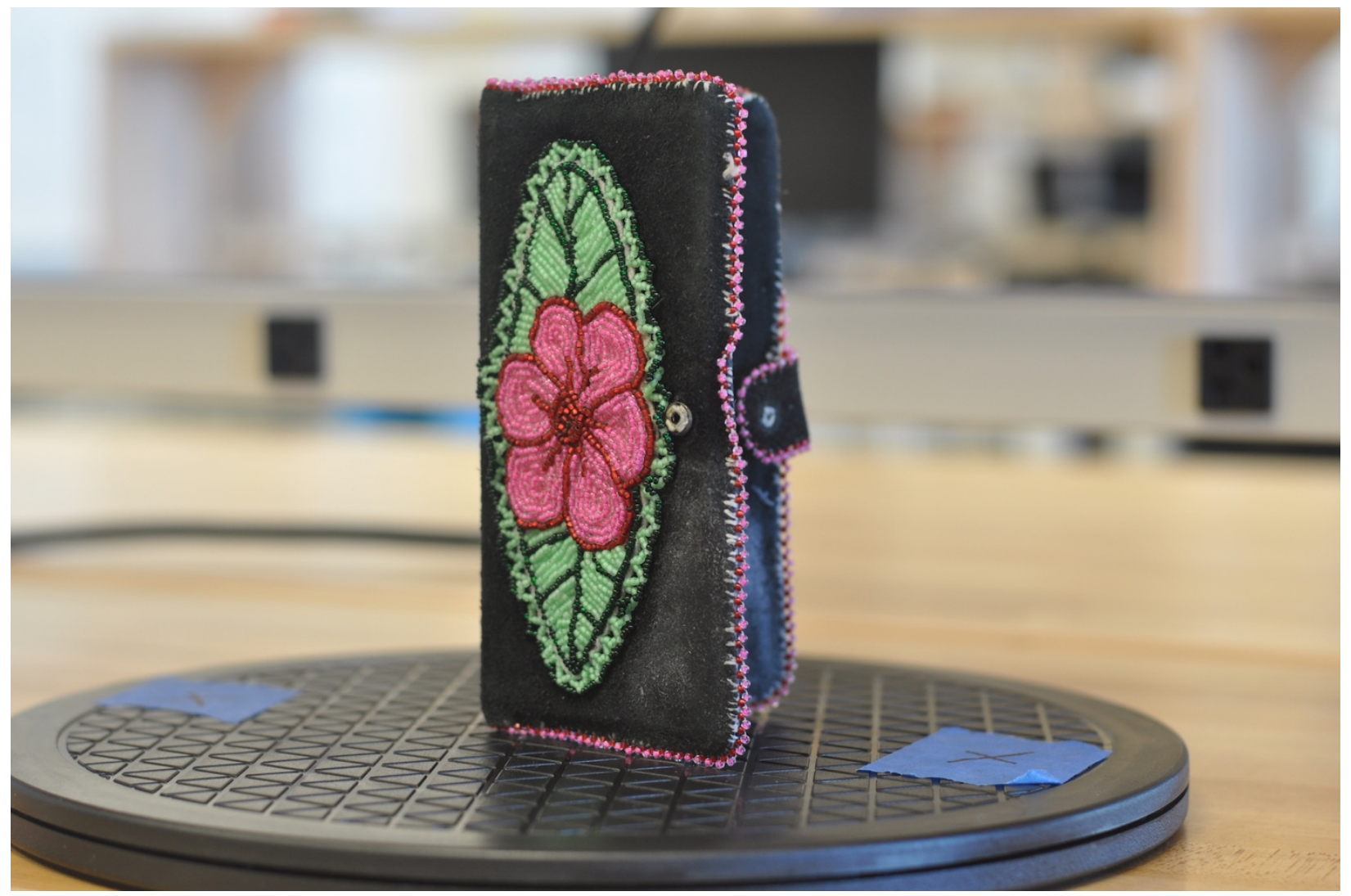

Figure 1. Checkbook made by Nina Kvasnikoff. Two-dimensional images of checkbook. Photo by Alexandra Taitt.

An alternative to 3D scanning is a modeling process that uses photogrammetry and SFM. Photogrammetry, the use of photography in surveying and mapping to measure distances between 
objects (Gienko 2010), is as old as modern photography. It results in maps, drawings, measurements, or 3D models of some kind that portray an actual object or location. SFM is one method of photogrammetry that offers a low-cost alternative to many other photogrammetric procedures available. SFM is founded on the idea of stereoscopic photogrammetry, which requires a series of overlapping and offset photographs to construct a 3D model of an object or scene (Gienko and Terry 2014; Westoby et al. 2012). Construction of the 3D model depends completely on the exact position of any given photograph. Unlike costly scanners, SFM requires only camera equipment and processing software. Even photos taken on a point-and-shoot camera or smartphone can be used to create a working 3D model. The key to good SFM 3D models is to start off with good photographs. Photos can be taken on-site and later uploaded to the software application for construction. 


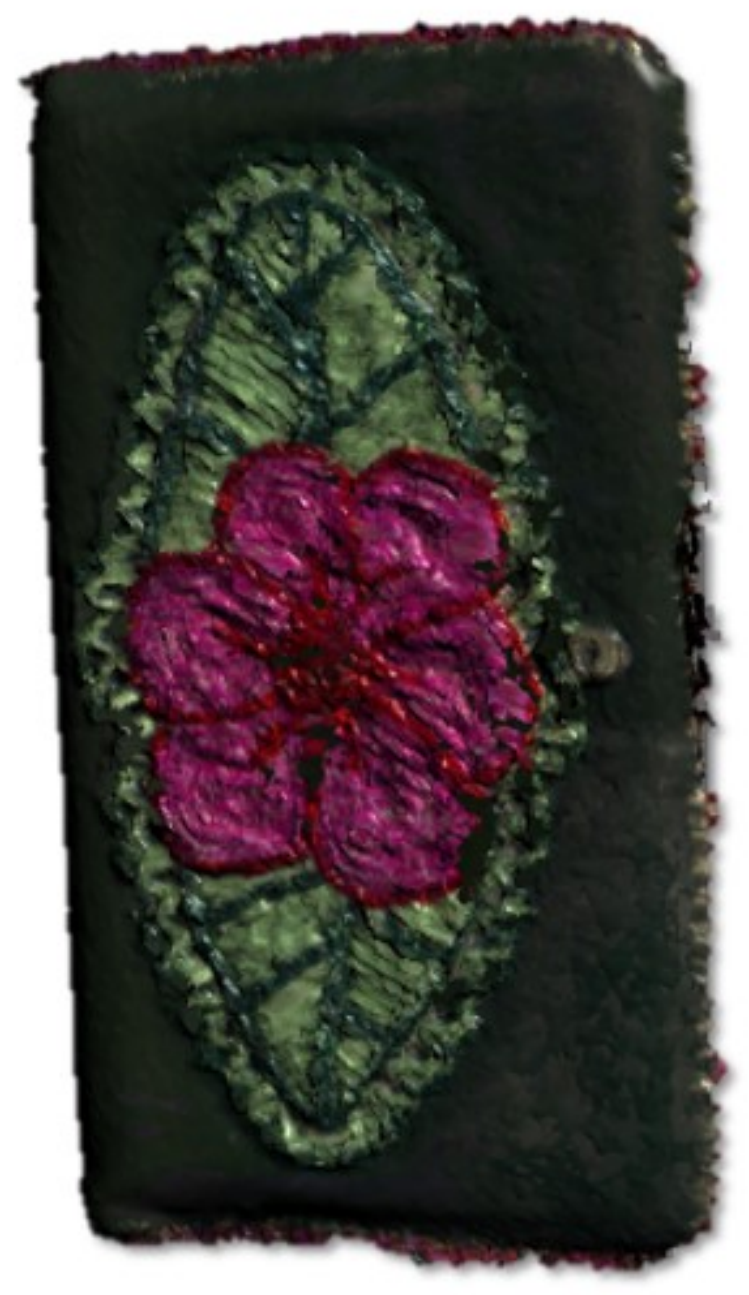

Figure 2. Checkbook made by Nina Kvasnikoff. Image of laser-scanned 3D model. Model by Alexandra Taitt. 


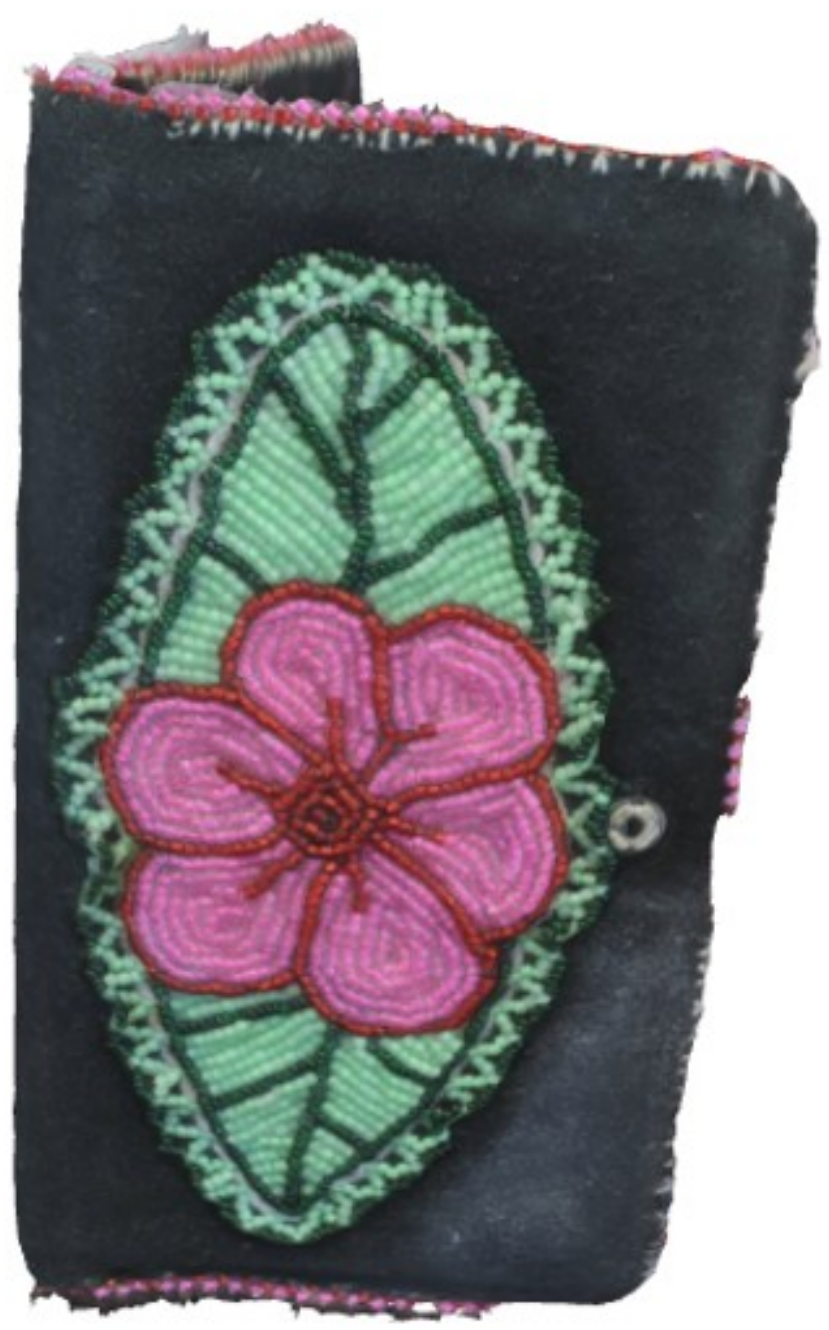

Figure 3. Checkbook made by Nina Kvasnikoff. Image of 3D SFM model created with Agisoft PhotoScan. Model by Alexandra Taitt.

SFM was selected for this project based, in part, on the quality of 3D models of ethnographic collection pieces that were far superior when compared with 3D scanned models. The leather checkbook cover with appliqué beadwork (figure 1) by Sugpiaq artist Nina Kvasnikoff demonstrates these differences. When comparing the laser-scanned model (figure 2) and the SFM model (figure 3), the latter far exceeds the quality of the former. There are still some imperfections with the SFM model, including repeated texturing on the inside of the checkbook and some jagged edges, but the level of detail and quality compared to the laser-scanned model is definite. Based on the photorealism of the SFM model and the ease of transporting equipment for data collection, SFM was the most appropriate choice for creating 3D representations of these ethnographic pieces. 
The process of SFM begins with a series of technical photographs of the target object (figure 4). These photos should cover multiple views of the object, ideally covering the entire object at multiple angles.

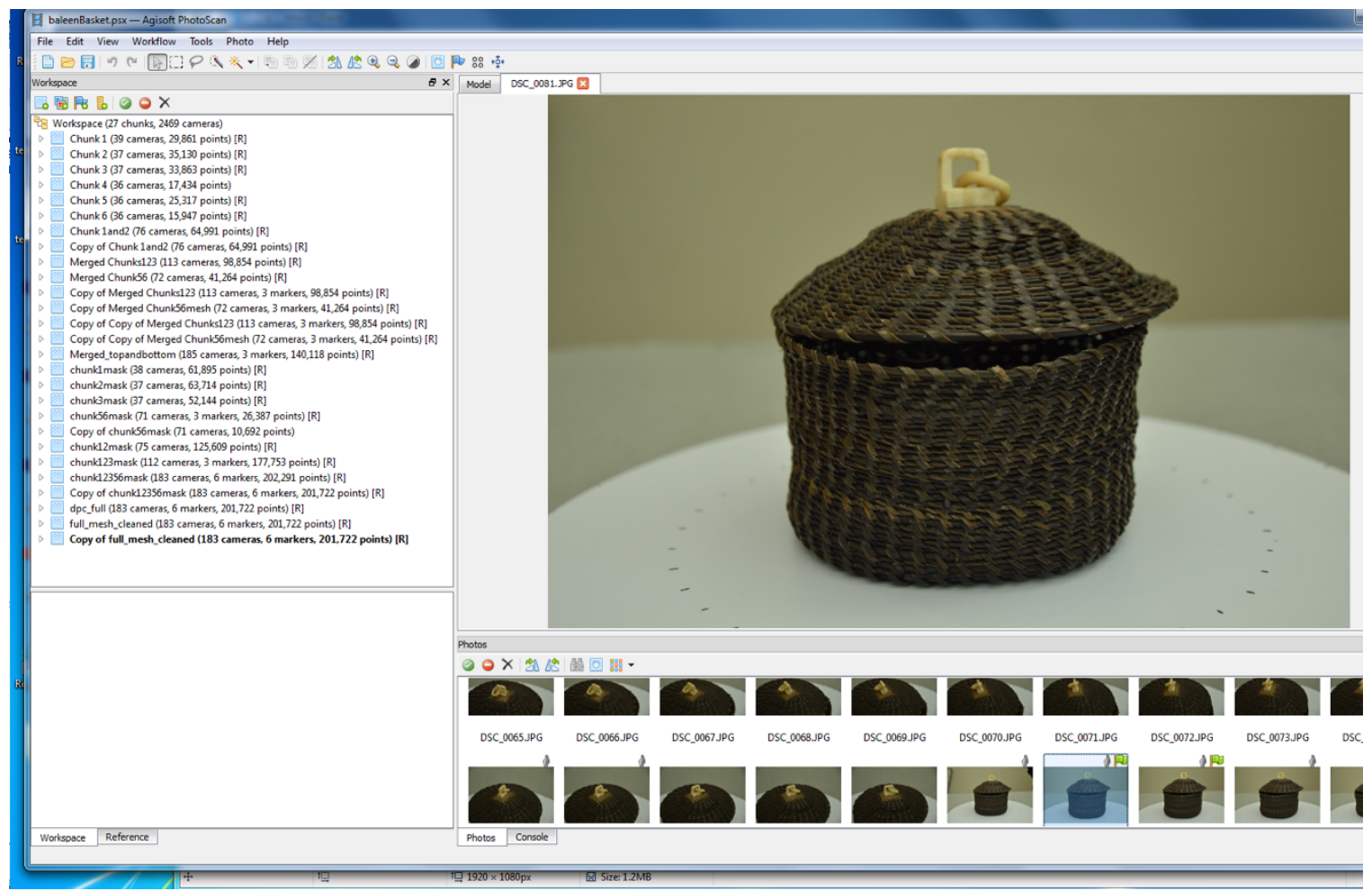

Figure 4. Iñupiaq baleen basket by John Backland Jr., c. 1930. The basket is from the collection of the Wells Fargo Alaska Heritage Museum in Anchorage, Alaska (accession \# 10188).

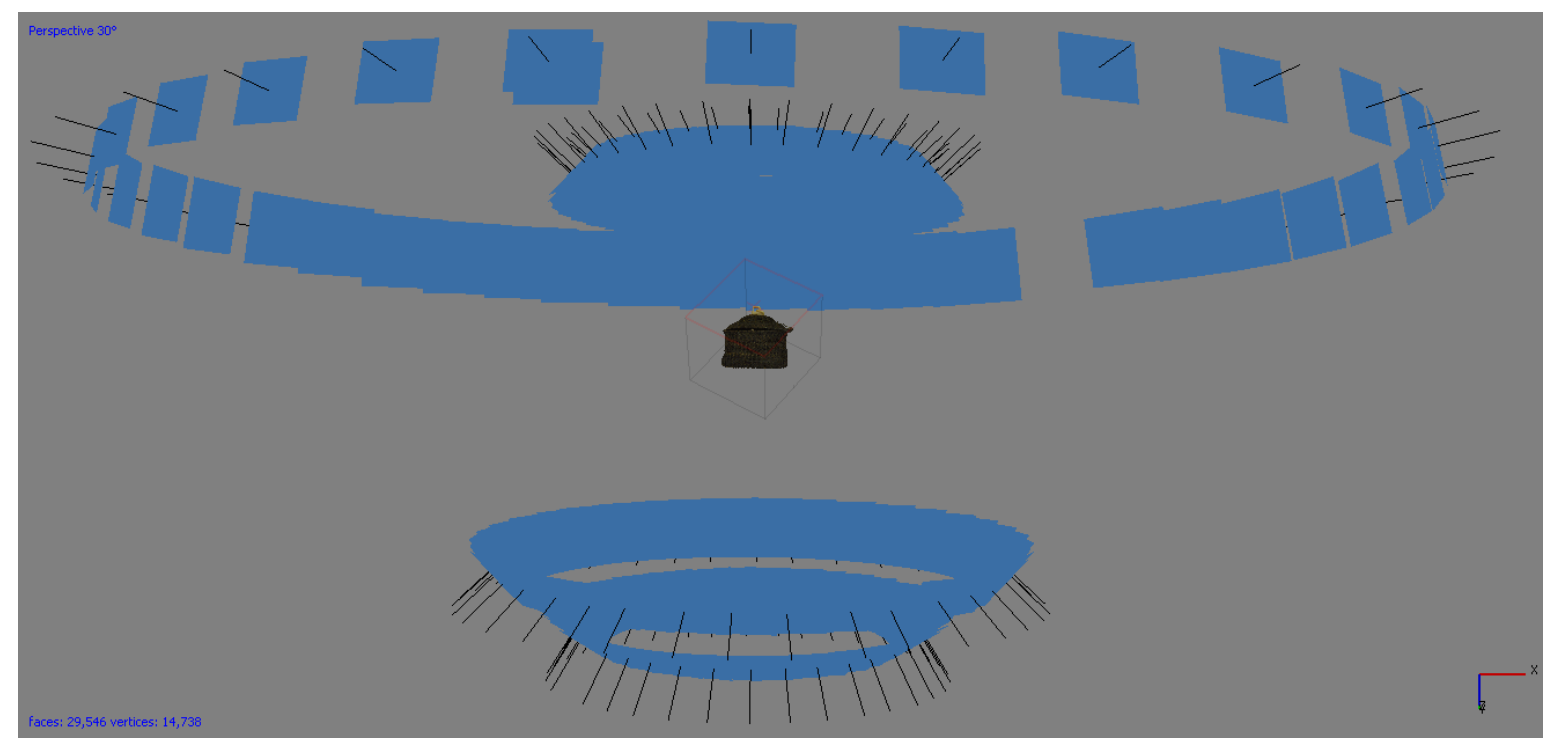

Figure 5. All the images aligned around the model. 
While full coverage is desirable, even documenting only one side of an object can produce a partial 3D model. After the photos are captured, they are imported into a specialized software program (e.g., Agisoft PhotoScan) for the computationally complex portion of the process. To enhance point selection and precision, the photographs can be masked, which includes cutting out or hiding everything in the background that is not necessary for the 3D model. Once the photographs are masked, the physical, geospatial locations are calculated in a procedure that aligns all of the separate images into the beginning stages of a model (figure 5).

After the photographs are aligned and every corresponding and concurrent point is identified (figure 6), a series of more computationally intensive algorithms begins to extrapolate each intermediate step into a more complete version of the model.

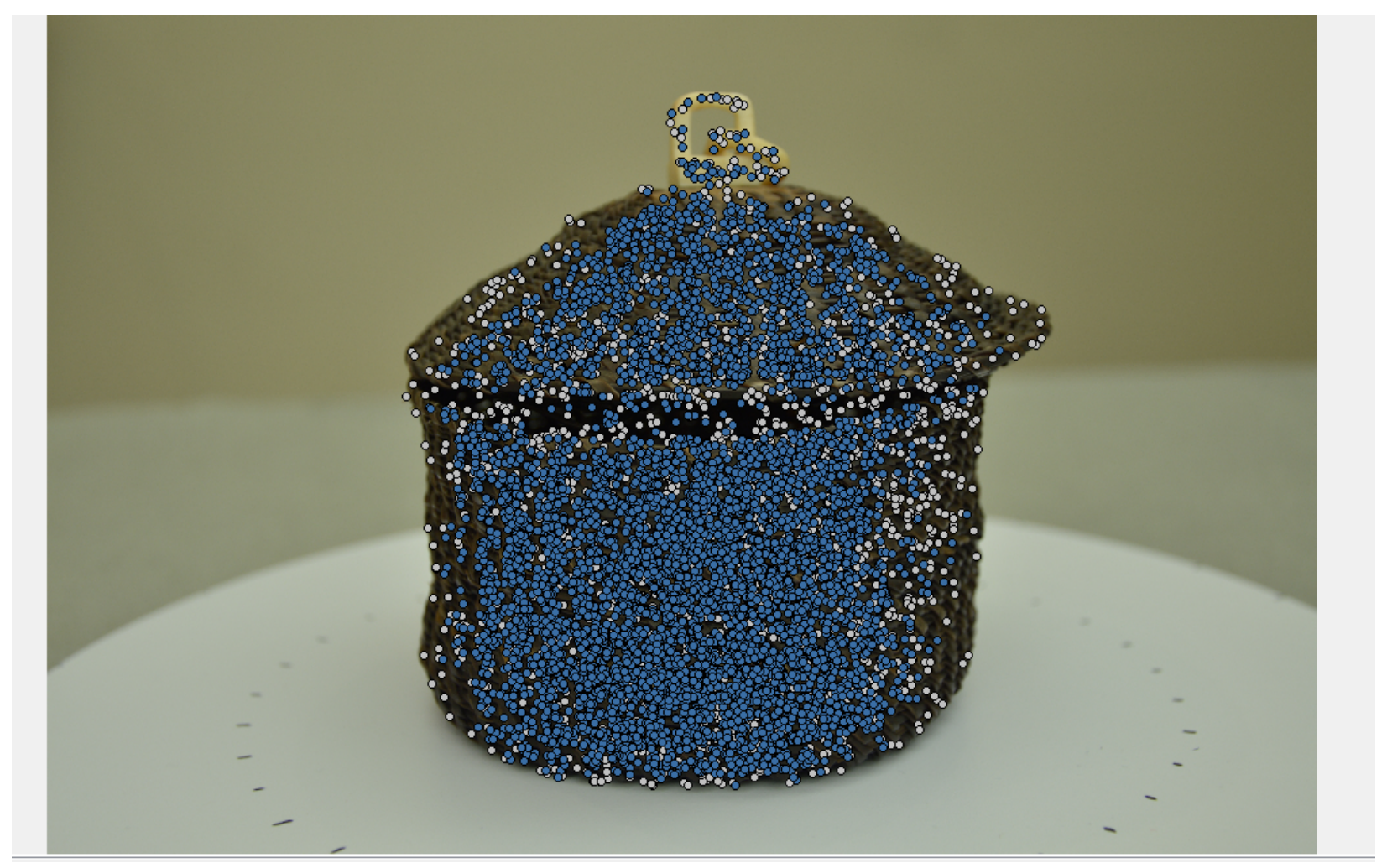

Figure 6. Each blue point can also be found on another image and is used in creating the model, while the gray points are not used.

Using the synchronized points identified in the photographs, a sparse point cloud (figure 7) is constructed, displaying the very basic representation of the object. Those points are then further extrapolated to create a dense point cloud (figure 8). After intermittent cleaning of nonessential or outlier points, the actual model construction begins. This does not happen until the mesh is created in the following step, which essentially connects each significant set of points to form a triangular mesh. This is known as the wire frame, representing the skeleton or main support structure of the 3D model (figure 9). One of the final steps returns to the original set of photographs and uses them to create a texture, or skin-like covering, to lay down on top of the triangular mesh (figure 10). 
The textured mesh is the final model, producing a 3D digital artifact with clear detail, depending on the quality of the original photographs (figure 11).

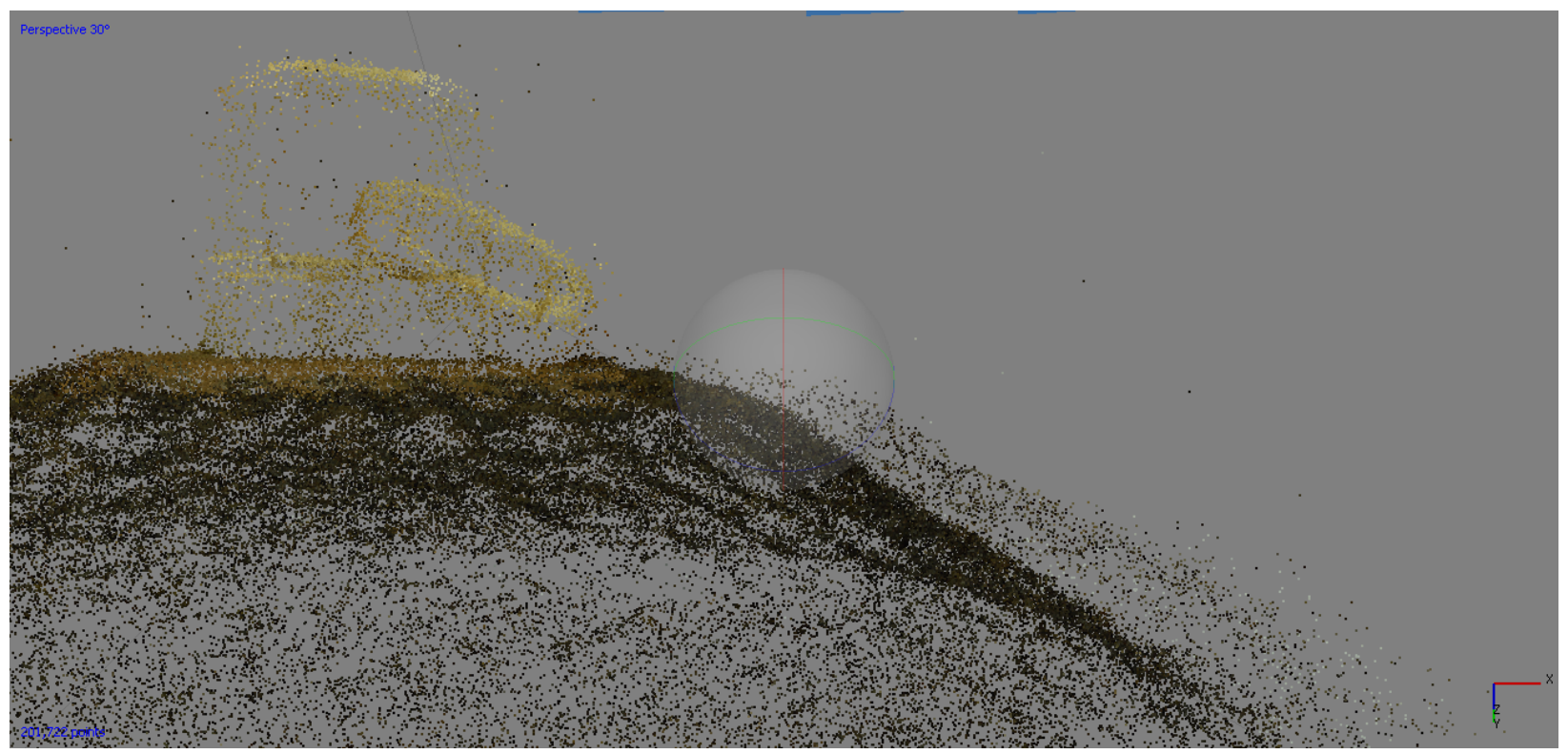

Figure 7. Sparse point cloud.

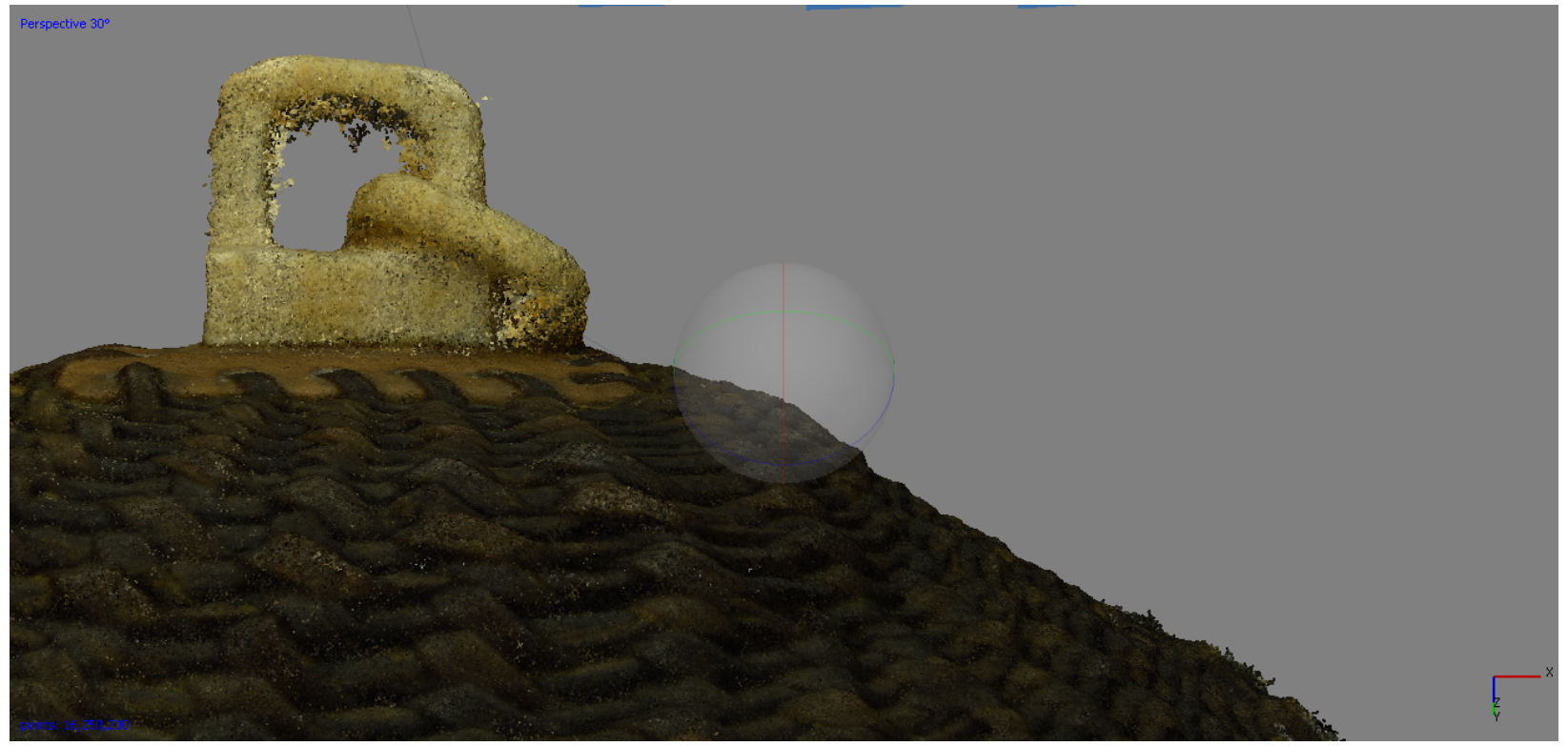

Figure 8. Dense point cloud. 


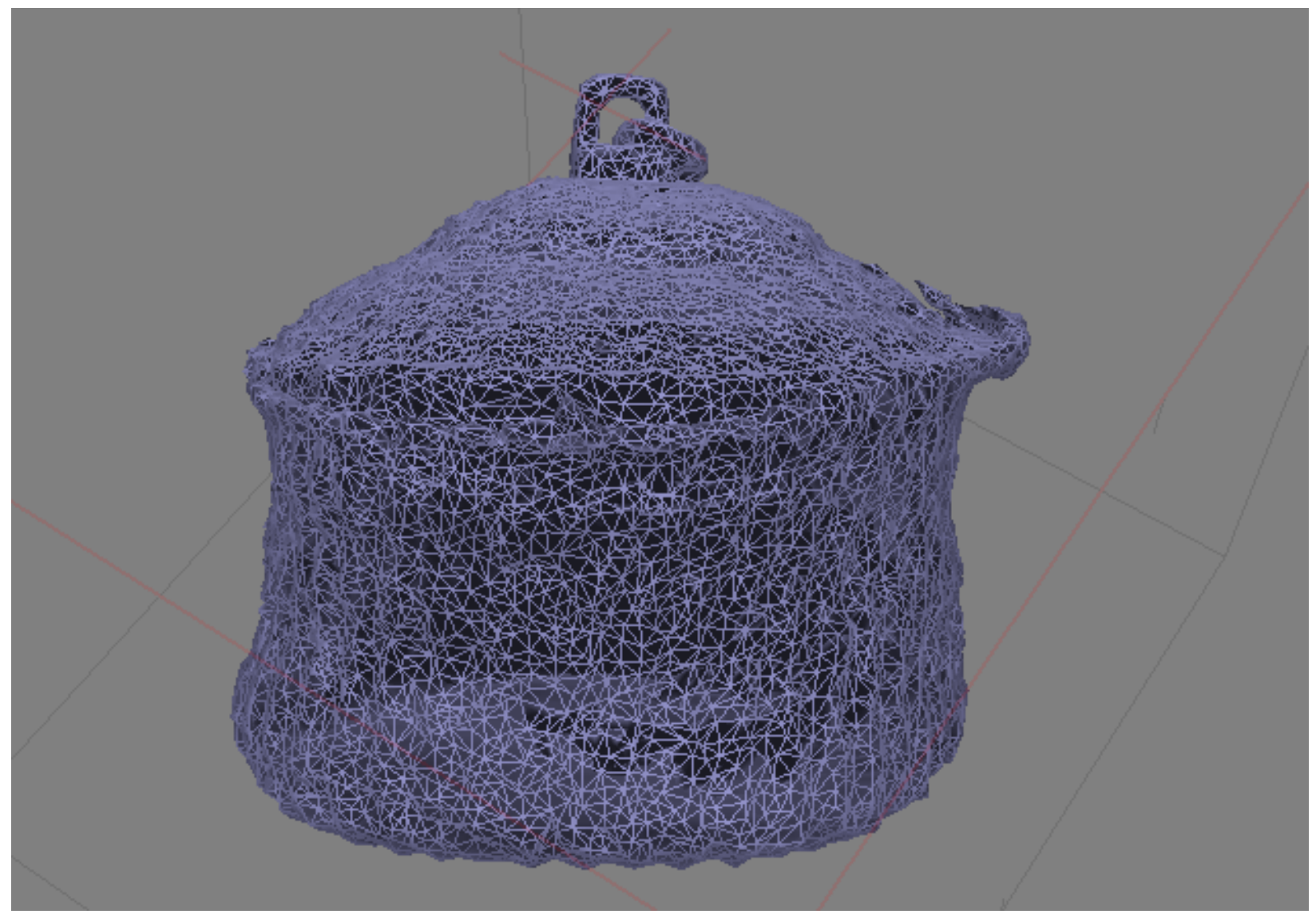

Figure 9. Mesh structure of the model.

SFM does, however, have some weaknesses. Although the process is still relatively less expensive than 3D scanners, the software can be costly, especially for groups with limited funding. There are many options for photogrammetry software, from free open-source applications to expensive industry-standard programs. Both ends of the spectrum can be beneficial, depending on the goals of the project. Some examples of open-source software include Bundler, VisualSFM, MicMac, and MVE. These software options range in quality of results, with varying degrees of user-friendly software interfaces. Of the proprietary software, PhotoModeler, RealityCapture, 3DF Zephyr, and Agisoft PhotoScan are a few of the more mainstream options available. All three offer semiautomatic modeling with high-quality results at varying price points. Extensive use of the PhotoScan software has also resulted in a user-generated community for support and tutorials, as well as a special interest group dedicated to use of the software for cultural heritage preservation. 


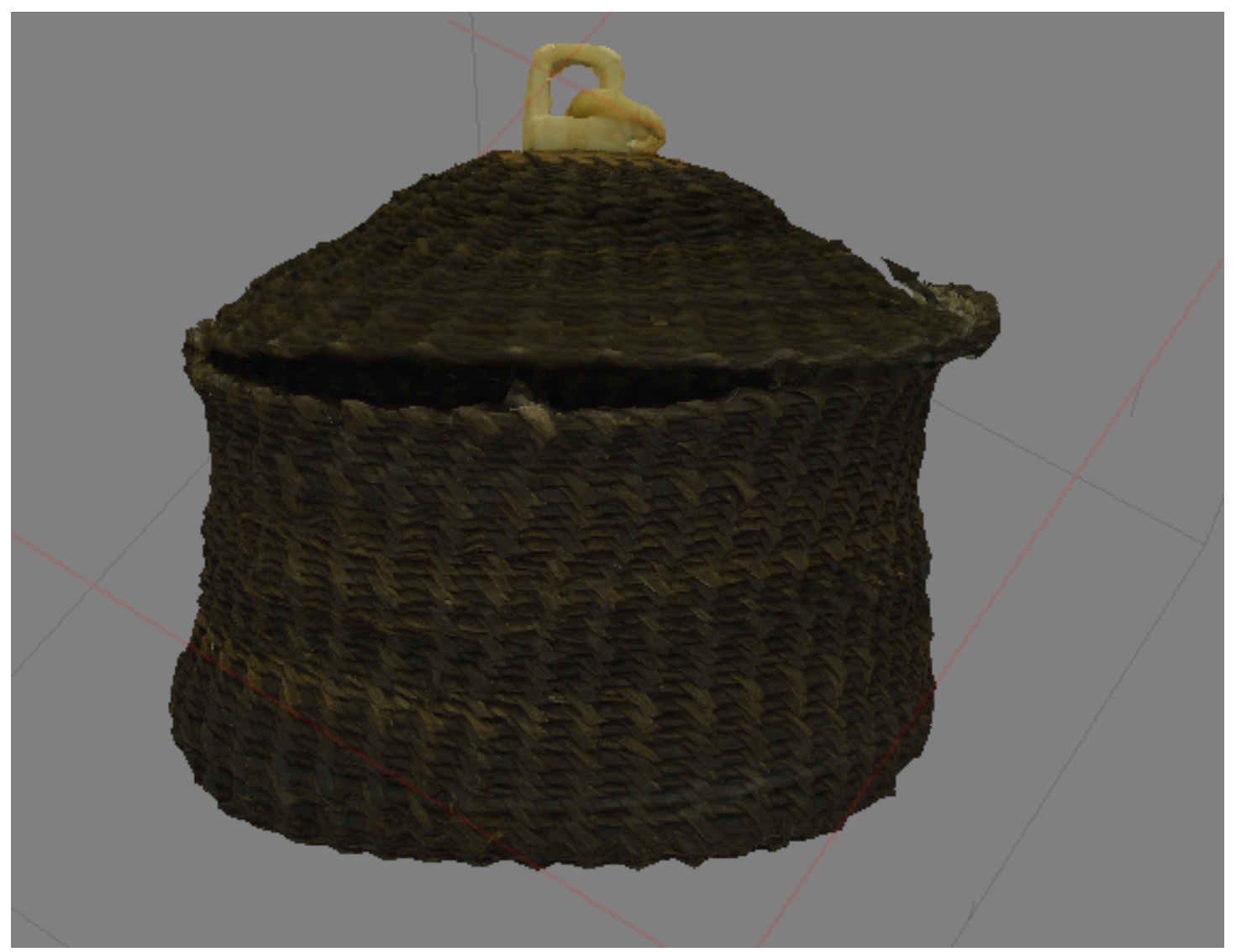

Figure 10. Surface texture added to the model.

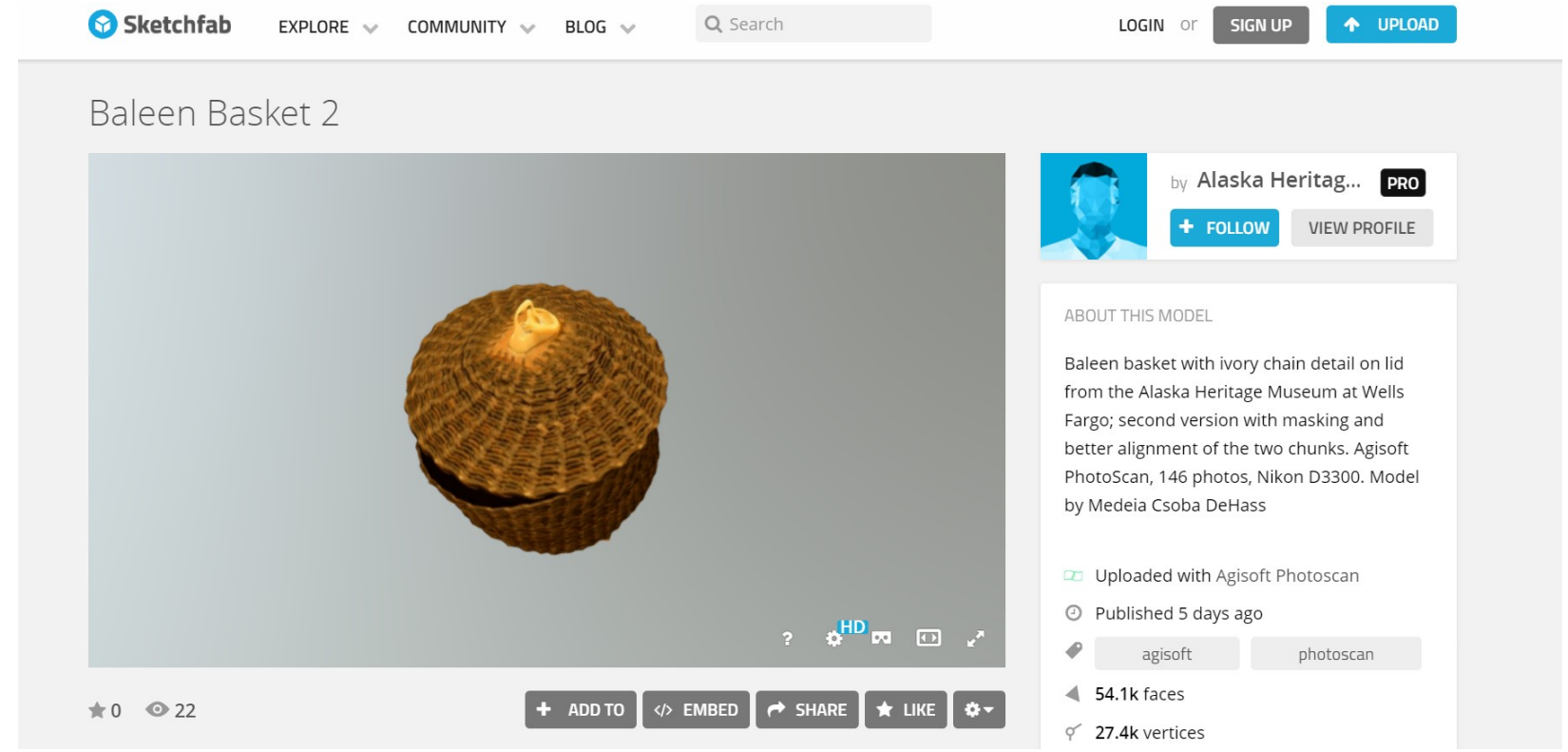

Figure 11. Interactive 3D model of the Baleen Basket on Sketchfab. 
As with any situation involving technical software, there is also a learning curve associated with constructing the 3D models. While many applications have streamlined the overall process, additional steps and procedures must be completed to produce a presentable model. Technical photography is another important component of the SFM method. Using the appropriate settings, lighting, and lenses can mean a major difference in the quality of a model. While soft materials that are difficult to obtain in 3D scans are still tricky to capture in SFM, using a suitable lens and filter can produce a much-higher-quality model (figure 12). It is also necessary to determine the balance between time spent on creating the models and the quality of the models required for the purposes of the particular project, as "there is no fixed point at which a digital model of a heritage artefact can be said to be "complete"' (Younan and Treadaway 2015, 241).

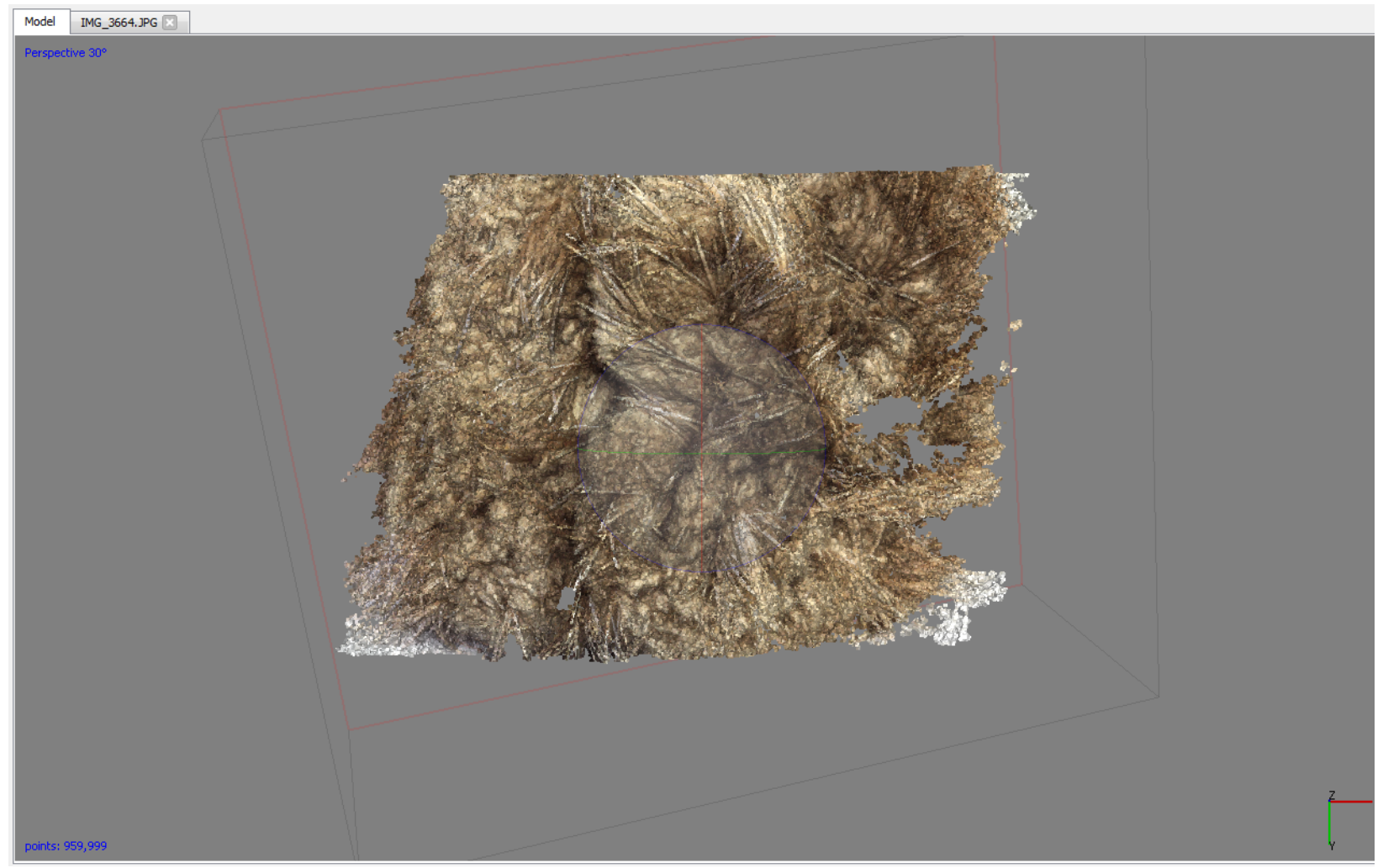

Figure 12. Fur, one of the most prevalent materials in Arctic and Subarctic Indigenous collections, is particularly difficult to 3D model. The above dense cloud sample is sheared beaver fur from a contemporary, commercially sold earmuff. The photos were taken as an experiment using a macro lens, which made it possible to find matching points. An Interactive 3D model of the fur sample can be viewed on Sketchfab

(https://sketchfab.com/models/a4d79bd721e2497fa5c8766a3eb17485). Model by Medeia Csoba DeHass.

Displaying, sharing, and archiving the 3D models are other considerations that must be taken into account. While there is free software (e.g., MeshLab) available for users to download and view the specific file types associated with the models, this approach is not convenient for end users with little to no experience working with technical software paired with the excessively large file sizes (Corns et al. 2015). 
A more practical approach has been the use of 3D PDFs. Ideally, anyone with access to a PDF viewer can open the file and view the general functionality of the $3 \mathrm{D}$ model without having to download additional software. Although this method has the potential to reach a larger population, there are some limitations. Users are required to download the file and must ensure their software is up to date to view the file. While these are only small obstacles, it may be difficult to provide user support to overcome the various steps needed to view the 3D PDF.

Another alternative that may prove to be more accessible and user-friendly is the use of third-party 3D model-hosting platforms, such as Sketchfab. This site serves as a repository for 3D and virtualreality content, which can then be shared and embedded on a number of websites and environments. There are also some limited controls for password-restricted access. Since the models are hosted on a third-party site, they can be viewed by anyone without having to download additional software or navigate through cumbersome steps. Sketchfab offers easy sharing and embedding, group access, and the ability to switch on virtual-reality mode, which enables users to connect with 3D viewing tools (e.g., Oculus Rift, Google Glass, Google Cardboard). Finally, 3D models can be displayed on html pages by using a variety of applications, but all of these require prior coding experience.

When it comes to digitizing heritage and making it available on the internet, it is crucial to keep in mind the target user audience and potential digital innovations. Because the average visitors of 3D heritage preservation platforms are not information technology professionals and are not prepared to operate a complicated 3D interactive site or model (Benedetto et al. 2014, 19), integrating and streamlining applications as much as the current technology allows clearly promotes accessibility and increases usage.

One of the unresolved questions faced by projects creating 3D models of ethnographic collections is that of archiving. Although there are repositories focusing on digital artifacts, these large, publicly accessible data repositories are often not a good solution for digital repatriation projects. The question comes down to the aim of the digital repatriation: returning some type of information or knowledge to an origin or descendant community in a digital form. This is impossible to achieve without major contributions from the community and a decision-making process that privileges the origin community's perspective. For these reasons, it is common to establish some form of culturally appropriate restrictions on access to some or all of the digitally repatriated items, including 3D models. It is also important to consider the ownership of the point clouds in terms of cultural property rights and acknowledgment of the creators. There is a difference between displaying 3D models or visualizing the item and providing free access to point clouds that share the data, which is the digital artifact that carries information needed for the re-creation or 3D printing. The former is negotiated to follow cultural protocols, but the latter should be treated as the choice of the origin community. There is also a difference between memory institutions 3D modeling their collection pieces and making them available online and 3D models contextualized on a platform with input from the local community in order to digitally repatriate culturally specific information. The former is created to display the institution's collection pieces, and the latter is created to share information in a way that conforms to the community's ideas of what should be known about them and the way this knowledge should be presented. Currently, archiving 3D models and point clouds as part of a digital repatriation project does not have an established 
protocol, and it is usually an agreement negotiated on a case-by-case basis with input from all stakeholders.

\section{Digital 3D Models in Decolonizing Collections}

While 3D digitization, like many other new technologies, was initially not specifically developed for heritage preservation, museums, scholars, and origin communities quickly became interested in exploring how it could contribute to their collections management goals. In general, new technologies develop faster than we are able to completely ascertain their full potentials. Moreover, humans are ingenious when it comes to reinterpreting a new technology to fit a variety of cultural experiences (DeHass 2014). For these reasons, we cannot know the exact effect and outcomes of using 3D models for the purposes of preserving cultural heritage and providing access and a digital form of artifacts to their origin communities. Yet, we can reflect on some of the current research results and contemplate their future significance and potential impacts.

The first aspect, using 3D models in collections management and curation to balance preservation concerns and access to information about the objects, has been discussed in many of the early studies. The advantage of making a high-quality 3D model available to the public to view and work with while the original objects are safely kept in controlled environments was one of the primary motivations behind adapting 3D technologies for the purposes of preserving cultural heritage. As it turns out, the argument can be made for the reverse usage as well. Threedimensional models can provide access to items that are contaminated with preservative chemicals that can pose health concerns. Access, whether it is $24 / 7$ or controlled through culturally appropriate limitations, to 3D models of these items provides opportunities for the public to engage with new knowledge and bring previously unknown material into scholarly discourse. Furthermore, when 3D models are contextualized in a curated digital repatriation platform, they can contribute to generating new sources of Indigenous cultural knowledge that can reenter the origin community and shape a variety of social and cultural processes, including attaining a voice in cultural representation. In this process, what is being repatriated is not the item itself but the culturally specific knowledge about the existence of, the techniques used to create, and the proper way to contextualize the item, all of which did originate in the community. Therefore, using the term repatriation is fully accurate and signifies the return of intangible cultural heritage that is prized by the origin community.

Recasting digital repatriation in this light allows for perceiving it as a complementary method to, and a possible step toward, physical repatriation. Sharing 3D models with origin communities within the larger framework of a collaborative project disseminates information and raises awareness about the existence of previously unknown artifacts. Using the newly generated information to enrich digital repatriation platforms increases communication among collections, institutions, and local communities. The details available through 3D models add a layer of information to knowledge-sharing networks. Contextualized and collaboratively built databases make collection pieces easily accessible even at remote locations, as in small communities strewn across the Circumpolar North, and promote the significance of being invested in such data-sharing projects. This investment can foster returning and dedicated users who can participate with contributions at their own level of comfort. While the digital divide greatly affects rural areas of 
the Circumpolar North, including Alaska (Hudson 2015), and poor internet connections in origin communities must be taken into consideration when designing digital repatriation platforms, digital 3D models can also be shared using mobile data storage, such as external hard drives, that are accessible to local community members.

In addition to providing access to already existing museum collections, 3D models and collaborative databases can be used in a reverse direction. As Jim Enote candidly pointed out during the After the Return: Digital Repatriation and the Circulation of Indigenous Knowledge workshop held at the Smithsonian Institution's National Museum of Natural History (NMNH) in Washington, DC on January 19-21, 2012, “if digital surrogates were so good . . why didn't the institutions, researchers, and scholars keep them, and return the original, non-digitized, analog object to the community themselves?" (in Bell et al. 2013, 7-8). When it comes down to it, nowhere is it written that origin communities are the ones who have to have the 3D models while the actual artifacts are placed with heritage institutions. In fact, quite the opposite is true. Creating 3D models of items in origin communities for the purposes of information sharing and scholarly study not only allows for the documentation of pieces without ever removing them from the ownership of the community but also significantly contributes to the decolonization of museums and collections practices. Three-dimensional models in conjunction with collaboratively contextualized and curated databases make it possible to use an approach where nothing is physically removed from the community and no information is shared that is deemed inappropriate.

Despite the growing number of successful project models available to study and learn from, digital Indigenous studies, digital museum exhibitions, and in particular, the use of 3D technology and digital repatriation are still new techniques, concepts, and opportunities that will continue to shape immensely the future of interactions among origin communities, researchers, and museum collections. Increased interest and public access to museum collections also raise questions of professional ethics, intellectual property rights, ownership, and the politics of cultural representation entering a virtual context. Hennessy's (2009) short commentary on digital repatriation and digital cultural heritage and Jane Anderson and Kim Christen's (2013) work on traditional knowledge licenses and labels discuss many issues that can potentially lead partnerships into rough waters. For instance, ideas on the nature of the public/private dichotomy, cultural ownership in relation to legal property rights, practices of reconciliation in regard to diverging histories, or collective desires in the embodiment of negotiated public representations are all concerns that are reshaped in a digital environment. As Hennessy points out, ideas about the right balance between limiting access and approving worldwide availability continually changes with increased exposure to technology, but it still leaves project participants with unresolved questions on enforcing cultural and property rights in a virtual context. In a similar vein, Anderson and Christen conclude the key rationale behind balancing access and protection in a digital environment, using Mukurtu CMS as an example, "is not about creating digital locks for materials, but instead, about respecting and representing the range and types of relationships people have with digital materials" (Anderson and Christen 2013, 112).

Creating and circulating 3D models of items physically retained by their owners is a significant aspect of 3D technology that can go a long way in decolonizing past practices of assembling museum collections. Artifacts will never need to physically leave their origin communities when 
3D modeling takes place on location. Moreover, using 3D technology provides tools and opportunities to reconsider the notion of digital repatriation as a complementary option for bringing collection pieces and origin communities together in a virtual space - not to replace the possibility of physical repatriation, but to bridge the time and space divide that exists between most Indigenous collection pieces and the descendants of those who created and owned them. For these reasons, and incorporating viewpoints recently expressed in the context of Arctic, and specifically Alaska Native, collections, using 3D technology redefines what digital repatriation is, or can be, for a variety of Indigenous communities. It also places a powerful tool in the hands of community members, cultural programs, students, and scholars, as well as institutional collection curators and managers who can engender new ways to work together from afar and across large geographical distances. Perhaps, somewhere in the near future, these collaborations can also lead to large undertakings, even at the scale of a virtual Arctic museum. These projects can bring together stakeholders while using 3D technology in a curated and collaborative heritage management platform to shed light on the forgotten corners of museums and to bring attention to pieces hidden on shelves or in the shadow of an already well-known artifact.

\section{Acknowledgments}

We would like to express our gratitude to Nina Kvasnikoff from the Native village of Nanwalek, Alaska, for the checkbook cover. We would also like to thank Tom Bennett, the curator and director of the Wells Fargo Alaska Heritage Museum, for working with us on multiple 3D projects; Dr. Gennady Gienko, for providing instructions in using SFM technology and the Agisoft PhotoScan software; and AI\&e at University of Alaska Anchorage for supporting this project through their Technology Innovation Grant. We would also like to acknowledge funding by Alaska Humanities Forum that supported the collaboration with Eva Malvich and express our gratitude to the anonymous reviewers of Museum Anthropology Review for their feedback.

\section{Notes}

1. Alutiiq or Sugpiaq is an Alaska Native cultural group with traditional lands located in Southcentral Alaska.

2. In 1971, the Alaska Native Claims Settlement Act (ANCSA) (http://ancsaregional.com/) created $12+1$ regional corporations and over two hundred village corporations for Alaska Native people to enroll in as shareholders. The corporations received 44 million acres of land and 962.5 million US dollars. In general, regional corporations owned the subsurface, and the village corporations owned the surface rights to the land. Alaska Native people had a choice to enroll both in a regional and in a village corporation with one hundred shares in each or to enroll only in a regional corporation as an "at large" shareholder. Alaska Native people born after the act was signed into law were not issued additional shares but were able to inherit them. Some of the ANCSA regional corporations opened up enrollment for all their shareholders' descendants after the 1991 amendments.

3. With the passing of NAGPRA in 1990, federal agencies, including museums and material heritage repositories, are required to repatriate specific Native American items that fit into one of four specific categories to origin communities. 
Article 12 of the United Nations Declaration on the Rights of Indigenous Peoples (UNDRIP) states the right to repatriation of human remains and the repatriation and/or access to ceremonial objects. However, while UN declarations "represent the dynamic development of international legal norms and reflect the commitment of states to move in certain directions" (United Nations, n.d.), they are not legally binding, and as such, the UNDRIP does not have the same legal requirements and consequences NAGPRA does.

4. In some Alaska Native cultural regions, such as Yup'ik and Sugpiaq areas, masks were burned or hidden in caves after the winter ceremonies concluded for that year. Masks were not supposed to be kept around and used outside of the ceremonies as they were a connection to the spirit world.

\section{References Cited}

Anderson, Jane, and Kim Christen. 2013. "“Chuck a Copyright on It': Dilemmas of Digital Return and the Possibilities for Traditional Knowledge Licenses and Labels.” Museum Anthropology Review 7 (1-2): 105-126.

Basu, Paul. 2013. "Reanimating Cultural Heritage: Digital Curatorship, Knowledge Networks and Social Transformation in Sierra Leone." In Museum Transformations: Art, Culture, History. The International Handbooks of Museum Studies, edited by Annie E. Coombes and Ruth B. Phillips, 337-364. Oxford: Wiley-Blackwell. https://doi.org/10.1002/9781118829059.wbihms994

Bell, Joshua A. 2015. "The Veracity of Form: Transforming Knowledges and Their Forms in the Purari Delta of Papua New Guinea." In Museum as a Process: Translating Local and Global Knowledges, edited by Raymond A. Silverman, 105-122. London: Routledge.

Bell, Joshua A., Kimberly Christen, and Mark Turin. 2013. "Introduction: After the Return." Museum Anthropology Review 7 (1-2): 1-21.

Black, Martha. 2013. Collaborations: A Historical Perspective. In Native Art of the Northwest Coast: A History of Changing Ideas, edited by Charlotte Townsend-Gault, Jennifer Kramer, and Ki-Ke-In, 785-827. Vancouver: University of British Columbia Press.

Boast, Robin, and Jim Enote. 2013. "Virtual Repatriation: It Is neither Virtual nor Repatriation." In Heritage in the Context of Globalization: Europe and the Americas, edited by Peter F. Biehl, 103-116. New York: Springer.

Bohaker, Heidi, Alan Ojig Corbiere, and Ruth B. Phillips. 2015. "Wampum Unites Us: Digital Access, Interdisciplinary and Indigenous Knowledge - Situating the GRASAC Knowledge Sharing Database.” In Museum as a Process: Translating Local and Global Knowledges, edited by Raymond A. Silverman, 45-66. London: Routledge. 
Boserup, Ivan. 2005. "The Manuscript and the Internet: Digital Repatriation of Cultural Heritage." International Federation of Library Associations and Institutions 31 (2): 169173. https://doi.org/10.1177/0340035205054881

Brown, Alison K., and Laura Peers, eds. 2003. Museums and Source Communities: A Routledge Reader. London: Routledge.

Brown, Deidre, and George Nicholas. 2012. "Protecting Indigenous Cultural Property in the Age of Digital Democracy: Institutional and Communal Responses to Canadian First Nations and Māori Heritage Concerns.” Journal of Material Culture 17 (3): 307-324. https://doi.org/10.1177/1359183512454065

Bruno, Fabio, Stefano Brunoa, Giovanna De Sensib, Maria-Laura Luchia, Stefania Mancusoc, and Maurizio Muzzupappaa. 2010. "From 3D Reconstruction to Virtual Reality: A Complete Methodology for Digital Archaeological Exhibition.” Journal of Cultural Heritage 11 (1): 42-49. https://doi.org/10.1016/j.culher.2009.02.006

Burdick, Anne., Johanna. Drucker, Peter Lunenfeld, Todd Presner, and Jeffery Schnapp. 2012. Digital Humanities. Cambridge, MA: MIT Press.

Callet, Patrick. 2014. “3D Reconstruction from 3D Cultural Heritage Models.” In 3D Research Challenges in Cultural Heritage, edited by Marinos Ioannides and Ewald Quak, 135-142. Berlin: Springer. https://doi.org/10.1007/978-3-662-44630-0_10

Christen, Kimberly. 2009. "Access and Accountability: The Ecology of Information Sharing in the Digital Age." Anthropology News (April): 4-5. https://doi.org/10.1111/j.15563502.2009.50404.x

Corns, Anthony, Aaron Deevy, Gary Devlin, Louise Kennedy, and Robert Shaw. 2015. "3DICONS: Digitizing Cultural Heritage Structures." New Review of Information Networking 20 (1-2): 59-65. https://doi.org/10.1080/13614576.2015.1115232

Csoba DeHass, Medeia. 2014. "Photographing Collection Pieces.” Nanwalek History [website]. Accessed June 8, 2018. https://nanwalekhistory.com/2014/05/31/photographingcollection-pieces/

Csoba DeHass, Medeia, ed. 2014. Sugpiaq Catalog: Lower Kenai Peninsula Sugpiaq Material Culture and Heritage Preservation Project. Homer: Pratt Museum. http://www.prattmuseum.org/wp-content/uploads/2014/10/Catalog-09-22-14-LowerKenai-Peninsula-Sugpiaq-Material.pdf

Dawson, Peter, Richard Levy, and Natasha Lyons. 2011. “'Breaking the Fourth Wall': 3D Virtual Worlds as Tools for Knowledge Repatriation in Archaeology." Journal of Social Archaeology 11 (3): 387-402. http://journals.sagepub.com/doi/10.1177/1469605311417064 
DeHass, David. 2014. Honda Country: Relocalization Through Technology in Nanwalek Alaska. PhD diss. University of Alaska Fairbanks. http://hdl.handle.net/11122/4800

Di Benedetto, Marco, Federico Ponchio, Luigi Malomo, Marco Callieri, Matteo Dellepiane, Paolo Cignoni, and Roberto Scopigno. 2014. "Web and Mobile Visualization for Cultural Heritage.” In 3D Research Challenges in Cultural Heritage, edited by Marinos Ioannides and Ewald Quak, 18-35. Berlin: Springer. https://doi.org/10.1007/978-3-662-44630-0 2

Eaton, Perry. 2009. "From the Artist's Point of View." In Giinaquq Like a Face: Sugpiaq Masks of the Kodiak Archipelago, edited by Sven D. Haakanson Jr. and Amy F. Steffian, 167172. Fairbanks: University of Alaska Press.

Fienup-Riordan, Ann. 2005. Yup'ik Elders at the Ethnologisches Museum Berlin: Fieldwork Turned on Its Head. Seattle: University of Washington Press.

Frontier Scientists. 2016. “Alutiiq Weavers.” Accessed June 8, 2018. http://frontierscientists.com/projects/human-history-science/alutiiq-weavers/

Gienko, Gennady. 2010. "Photogrammetric Methods." In Encyclopedia of Geography, edited by Barney Warf. Thousand Oaks, CA: Sage Publications. http://dx.doi.org/10.4135/9781412939591.n885

- - - . and James P. Terry. 2014. Three-Dimensional Modeling of Coastal Boulders Using Multi-view Image Measurements. Earth Surface Processes and Landforms 39 (7): 853864. https://doi.org/10.1002/esp.3485

Ginsburg, Patty. 2008. Two Journeys. A Companion to the Giinaquq: Like a Face Exhibition. Kodiak, AK: Alutiiq Museum and Archaeological Repository.

Glass, Aaron. 2015. "Indigenous Ontologies, Digital Futures: Plural Provenances and the Kwakwaka'wakw Collection in Berlin and Beyond.” In Museum as a Process:

Translating Local and Global Knowledges, edited by Raymond A. Silverman, 19-44. London: Routledge.

Glenbow Museum. 2008. Thule Whalebone House. [Digital Exhibition] Accessed June 8, 2018. http://www.glenbow.org/thule/

Haakanson, Sven D. Jr. 2012. "Using Collections to Explore Local Heritage: Lessons from the Alutiiq Museum.” Accessed June 8, 2018. https://youtu.be/clOF2uXKd4E

- - - 2014. "Repatriating Knowledge and Inspiring Change." WestMusings 2014: Sven Haakanson. Accessed June 8, 2018. https://youtu.be/InUX8HCWikQ

- - - 2015. Alaska Native Masks Panel. University of Alaska Anchorage Bookstore. Accessed June 8, 2018. https://youtu.be/S1OYFwjzaWM 
- - - . and Amy F. Steffian. 2009. Giinaquq Like a Face: Sugpiaq Masks of the Kodiak Archipelago. Fairbanks: University of Alaska Press.

Hennessy, Kate. 2009. "Virtual Repatriation and Digital Cultural Heritage: The Ethics of Managing Online Collections." Anthropology News 50 (4): 5-6. https://doi.org/10.1111/j.1556-3502.2009.50405.x

- - - ., Natasha Lyons, Stephen Loring, Charles Arnold, Mervin Joe, Albert Elias, and James Pokiak. 2013. "The Inuvialuit Living History Project Digital Return as the Forging of Relationships between Institutions, People, and Data." Museum Anthropology Review 7 (1-2): 44-73.

Hollinger, Eric R., Edwell John Jr., Harold Jacobs, Lora Moran-Collins, Carolyn Thome, Jonathan Zastrow, Adam Metallo, Günter Waibel, and Vince Rossi. 2013. "TlingitSmithsonian Collaborations with 3D Digitization of Cultural Objects." Museum Anthropology Review 7 (1-2): 121-253.

Hudson, Heather. 2015. Connecting Alaskans: Telecommunication in Alaska from Telegraph to Broadband. Chicago: University of Chicago Press.

Karl, Raimund, Jonathan Roberts, Andrew Wilson, Katharina Möller, Helen C. Miles, Ben Edwards, Bernard Tiddeman, Frédéric Labrosse, and Emily La Trobe-Bateman. 2014. "Picture This! Community-Led Production of Alternative Views of the Heritage of Gwynedd.” Journal of Community Archaeology and Heritage 1 (1): 23-36. https://doi.org/10.1179/2051819613Z.0000000003

Lepola, Marcus. 2013. “Tavastehus gymnasiums Alaska-samlingar-Den Furuhjelmska donationen av etnografiska föremål 1863" (The Furuhjelm ethnographic collection of 1863 in the Tavastehus Gymnasium). In Finskt Museum 117 (2010-2011), edited by Ulrika Rosendahl and Anna Wessman, 46-66. Helsinki: Suomen Muinaismuistoyhdistys.

Leopold, Robert. 2013. "Articulating Culturally Sensitive Knowledge Online: A Cherokee Case Study." Museum Anthropology Review 7 (1-2): 85-104.

Looking Both Ways: Heritage and Identity of the Alutiiq People. n.d. Virtual Exhibition. [Previously accessible at: http://www.mnh.si.edu/lookingbothways/] Accessed via Internet Archive on June 8, 2018. https://web.archive.org/web/20090310173038/http://www.mnh.si.edu/lookingbothways/

Malvich, Eva. 2016. "Working for a Tribal Museum.” Interview with Medeia Csoba DeHass. Accessed June 8, 2018. https://youtu.be/b93NdJYO6FM.

Morphy, Howard. 2015. "Open Access versus the Culture of Protocols." In Museum as a Process: Translating Local and Global Knowledges, edited by Raymond A. Silverman, 90-104. London: Routledge. 
Muntean, Reese, Kate Hennessy, Alissa Antle, Susan Rowley, Jordan Wilson, and Brendan Matkin. 2015. "Peləw'k 'w - Belongings: A Tangible Interface for Intangible Cultural Heritage.” CITAR Journal 7 (2): 59-69. http://dx.doi.org/10.7559/citarj.v7i2.159

Odegaard, Nancy. 2004. “The Issue of Pesticide Contamination.” In Caring for American Indian Objects: A Practical and Cultural Guide, edited by Sherelyn Ogden, 69-81. St. Paul: Minnesota Historical Society Press.

- - - . and Alyce Sadongei. 2005. Old Poisons, New Problems: A Museum Resource for Managing Contaminated Cultural Materials. Walnut Creek, CA: AltaMira Press.

Patay-Horváth, András. 2014. "The Virtual 3D Reconstruction of the East Pediment of the Temple of Zeus at Olympia an Old Puzzle of Classical Archaeology in the Light of Recent Technologies." Digital Applications in Archaeology and Cultural Heritage 1 (1): 12-22. https://doi.org/10.1016/j.daach.2013.06.001

Pieraccini, Massimiliano, Gabriele Guidi, and Carlo Atzeni. 2001. “3D Digitizing of Cultural Heritage.” Journal of Cultural Heritage 2 (1): 63-70. https://doi.org/10.1016/S12962074(01)01108-6

Powell, Timothy B. 2016. "Digital Knowledge Sharing: Forging Partnerships between Scholars, Archives, and Indigenous Communities." Museum Anthropology Review 10 (2): 66-90. https://doi.org/10.14434/10.14434/mar.v10i2.20268

Pure Land Augmented Reality Edition. 2012. "Inside the Mogao Grottoes at Dunhuang." Accessed June 8, 2018. http://alive.scm.cityu.edu.hk/projects/alive/pure-land-ii-2012/

Resta, Paul E., Loriene Roy, Marty Kreipe de Montano, and Mark Christal. 2002. "Digital Repatriation: Virtual Museum Partnerships with Indigenous Peoples.” In Proceedings of the International Conference on Computers in Education, 1482-1483. New York: IEEE Conference Publications.

Rostkowski, Joëlle. 2012. "Chapter Five. Sven Haakanson, Director of the Alutiiq Museum, Kodiak, Alaska." In Conversation with Remarkable Native Americans, 29-36. Albany: State University of New York Press.

Rowley, Susan, Leona Sparrow, Dave Schaepe, Andrea Sanborn, Ulrike Radermacher, Ryan Wallace, Nicholas Jakobsen, Hannah Turner, Sivia Sadofsky, and Tristan Goffman. 2010. "Building an On-Line Research Community: The Reciprocal Research Network." In Museums and the Web 2010: Proceedings, edited by Jennifer Trant and David. Bearman. Toronto: Archives and Museum Informatics. http://www.archimuse.com/mw2010/papers/rowley/rowley.html

Salmond, Amiria. 2012. “Digital Subjects, Cultural Objects: Special Issue Introduction.” Journal of Material Culture 17 (3): 211-228. https://doi.org/10.1177/1359183512453531 
Scopigno, Roberto, Marco Callieri, Paolo Cignoni, Massimiliano Corsini, Matteo Dellepiane, Federico Ponchio, and Guido Ranzuglia. 2011. "3D Models for Cultural Heritage: Beyond Plain Visualization." Computer 44 (7): 48-55.

Shannon, Jennifer. 2015. "Projectishare.com: Sharing Our Past, Collecting for the Future.” In Museum as a Process: Translating Local and Global Knowledges, edited by Raymond A. Silverman, 67-89. London: Routledge.

Silverman, Raymond A. 2015. "Introduction: Museum as a Process." In Museum as a Process: Translating Local and Global Knowledges, edited by Raymond A. Silverman, 1-18. London: Routledge.

Solomon, Maui, and Susan Thorpe. 2012. "Taonga Moriori: Recording and Revival." Journal of Material Culture 17 (3): 245-263. https://doi.org/10.1177/1359183512453533

Stathopoulou, Ellie K., Andreas Georgopoulos, George Panagiotopoulos, and Dimitris. Kaliampakos. 2015. "Crowdsourcing Lost Cultural Heritage." ISPRS Annals of the Photogrammetry, Remote Sensing and Spatial Information Sciences, II-5/W3: 295-300. https://doi.org/10.5194/isprsannals-II-5-W3-295-2015

Tal, Ayellet. 2014. "3D Shape Analysis for Archaeology.” In A Roadmap in Digital Heritage Preservation on 3D Research Challenges in Cultural Heritage, edited by Marinos Ioannides and Ewald Quak, 50-63. New York: Springer. http://dx.doi.org/10.1007/978-3$\underline{662-44630-0 \quad 4}$

Turner, Hannah Elizabeth. 2015. "Information Infrastructures in the Museum: Documenting, Digitizing, and Practising Ethnographic Objects in the Smithsonian's Department of Anthropology." PhD diss., University of Toronto.

United Nations. n.d. "Indigenous Peoples, Indigenous Voices. FAQ-Declaration on the Rights of Indigenous Peoples.” Accessed June 8, 2018. http://www.un.org/esa/socdev/unpfii/documents/FAQsIndigenousdeclaration.pdf

Weber, Gerhard W. 2014. "Another Link between Archaeology and Anthropology: Virtual Anthropology." Digital Applications in Archaeology and Cultural Heritage 1 (1): 3-11. https://doi.org/10.1016/j.daach.2013.04.001

Westoby, Matthew J., James Brasington, Niel F. Glasser, Michael J. Hambrey, and J. M. Reynolds. 2012. "'Structure-from-Motion' Photogrammetry: A Low-cost, Effective Tool for Geoscience Applications.” Geomorphology 179: 300-314. https://doi.org/10.1016/j.geomorph.2012.08.021

Willmott, Cory, Alexandra Taitt, Mary Ann Corbiere, and Alan Corbiere. 2016. "Toward Language in Action: Agency-Oriented Application of the GRASAC Database for Anishinaabe Language Revitalization." Museum Anthropology Review 10 (2): 191-116. https://doi.org/10.14434/mar.v10i2.19322 
Younan, Sarah, and Cathy Treadaway. 2015. "Digital 3D Models of Heritage Artefacts: Towards a Digital Dream Space." Digital Applications in Archaeology and Cultural Heritage 2 (4): 240-247. https://doi.org/10.1016/j.daach.2015.11.001

Medeia Csoba DeHass is an Assistant Professor of Anthropology and Alaska Native Studies at the University of Alaska Anchorage. She is currently involved in several projects focusing on the digital preservation of Alaska Native heritage using 3D technology. Her work has appeared in Arctic Anthropology, Ethnology, and Études/Inuit/Studies. She is the editor of Sugpiaq Catalog: Lower Kenai Peninsula Sugpiaq Material Culture and Heritage Preservation Project (Homer, AK: Pratt Museum, 2014).

Alexandra Taitt is currently the Museum Program Specialist and Camp Director in the Department of Community Outreach and Partnerships at the Anchorage Museum. She recently completed her MA in Anthropology at the University of Alaska Anchorage with her thesis, "The Next Dimension of Representation: The Role of Photogrammetric 3D Modeling in Digital Heritage Preservation of Indigenous Material Culture.”

https://doi.org/10.14434/mar.v12i2.22428 